LBL-38306

UC-401

\title{
Twenty-Five Years of Artificial Photosynthesis at the Ernest orlando Lawrence Berkeley National Laboratory
}

\author{
John W. Otvos and Melvin Calvin \\ Structural Biology Division \\ Ernest Orlando Lawrence Berkeley National Laboratory \\ University of California \\ Berkeley, California 94720
}

February 1996

This work was supported in part by the Director, Office of Energy Research, Office of Basic Energy Sciences, Chemical Sciences Division, of the U.S. Department of Energy under Contract No. DE-AC03-76SF00098. 


\section{DISCLAMMER}

Portions of this document may be illegible in electronic image products. Images are produced from the best available original document. 


\section{TWENTY-FIVE YEARS OF ARTIFICIAL}

PHOTOSYNTHESIS RESEARCH AT

ERNEST ORLANDO LAWRENCE BERKELEY NATIONAL

LABORATORY

John W. Otvos and Melvin Calvin

February 1, 1996 
Twenty-Five Years of Artificial Photosynthesis

\title{
at the Ernest Orlando Lawrence Berkeley National Laboratory
}

John W. Otvos and Melvin Calvin

\author{
Structural Biology Division \\ Ernest Orlando Lawrence Berkeley National Laboratory \\ University of California, Berkeley, California 94720
}

\begin{abstract}
This report summarizes the research done on artificial photosynthesis by the Calvin Group between 1970 and 1995 when the program was terminated. It contains a compilation of the personnel involved, their status while active here, and, as far as possible, their present location and affiliation as well as a bibliography of their publications on artificial photosynthesis.
\end{abstract}




\section{Table of Contents}

\section{Page Number}

Introduction

1

The Four Steps of Artificial Photosynthesis

3

Photochemical Reduction of Carbon Dioxide

Prospects for the Future

Appendix I: Text of Article on Artificial

Photosynthesis by Bard and Fox

Bibliography: Artificial Photosynthesis Publications 20

Personnel of Artificial Photosynthesis Group

1970-1995

Index to Bibliography 
TWENTY-FIVE YEARS OF ARTIFICIAL PHOTOSYNTHESIS

RESEARCH AT ERNEST ORLANDO LAWRENCE BERKELEY

NATIONAL LABORATORY

\author{
John W. Otvos and Melvin Calvin \\ Structural Biology Division \\ Ernest Orlando Lawrence Berkeley National Laboratory \\ University of California
}

Berkeley, California 94720

\title{
Introduction
}

Research in "artificial photosynthesis" aims at developing a practical artificial photosynthetic system that uses sunlight to drive a thermodynamically uphill reaction of an abundant material to produce a fuel, which would thus be a form of stored solar energy. Our group has been active in such research ever since 1970 when Tributsch and Calvin ${ }^{1}$ were able to produce a photocurrent by illuminating adsorbed chlorophyll molecules at a semiconductor $(\mathrm{ZnO})$-solution interface. Our overall approach has been to use the knowledge gained from studies of green plant photosynthesis to construct artificial systems that mimic the four steps of the natural process: (1) absorption of visible light by a sensitizer; (2) charge separation across a phase boundary, the separation being energized by the excited sensitizer. (3) kinetic stabilization of the photoinduced electron transfer products by "mediators", i.e., electron donors and acceptors; (4) catalytic transformation of the mediators to final oxidized and reduced products. 
Over the years that this project has been active we have worked on all four features of artificial photosynthesis. We have used porphyrins as model sensitizers and derivatized them to alter their absorption spectra and also to give them surfactant properties that would locate them on membrane surfaces by covalently attaching one or more paraffinic chains to the molecule. To explore the important step of charge separation, we have successfully used vesicles, micelles, and colloidal silica particles to enhance the yields of primary photoproducts. We introduced the now common new mediator, propylviologen sulfonate, PVS, whose important property is its electrical neutrality, which allows it to approach a negatively-charged interface easily. When it accepts an electron from the sensitizer, it is repelled and moves away, thus retarding back-reaction and stabilizing the electron transfer. In order to study the mediation steps separately without the need of putting an entire system together, we have used sacrificial electron donors such as ethylenediamine tetraacetic acid (EDTA) or trianthanolamine (TEA) on the reduction side and sacrificial electron acceptors such as cobalt(III) ammines on the oxidation side to complete the electron transfer reaction.

At the end of Fiscal 1995 our research program is being terminated after a period of twenty-five years. This report summarizes the group's work over the years on the four aspects of the program by listing the participants of each part -- graduate students, postdoctoral scientists, and visiting faculty -- along with their specialized contributions in the form of original scientific articles, reviews, and $\mathrm{Ph} . \mathrm{D}$. theses. Where possible, we also give in the appendix their present positions and affiliations to indicate the breadth and impact of our program both geographically and institutionally.

Quite recently there appeared in Accounts of Chemical Research an excellent review of the present status of artificial photosynthesis, written by Allen J. Bard and Marye Anne 
Fox. LAllen J. Bard and Marye Anne Fox, "Artificial Photosynthesis: Solar Splitting of Water to Hydrogen and Oxygen". Acct. Chem. Res. 28, 141-145 (1995)[ We will refer to many sections of this review as we describe our own activities leading up to the present. The entire article is included in the Appendix. References to it are designated "Bard-Fox".

\section{The Four Steps of Artificial Photosynthesis}

\section{Step (1) -. Absorption of Visible Light by a Sensitizer.}

In order to achieve the desirable structure for an artificial photosynthesis system it is necessary to have the sentizier attached to an interface as will be discussed in Step (2). The charge transfer from the sensitizer across the interface is really the first important chemical step that takes place. In the early years, there was very important work done by William E. Ford, a graduate student, and Yohmei Okuno, a postdoctoral associate, on the synthesis of sensitizers that would be surface-active and thus self-assemble at the interface of a lipid-like substance such as a membrane and an aqueous solution. 17,20 Okuno and Ford used the porphyrin molecule as the chromophore for absorbing visible light and devised an improved preparation and purification method of surfactant porphyrins derived from the partial quaternization of meso-tetra-4-pyridyl porphyrin (TPYP) and the partial esterification of meso-tetra-4-carboxyphenyl porphyrin (TCPP). They synthesized mono-, di-, tri-, and tetra- quaternized porphyrins by their procedure and thus were able to attach long carbon alkyl chains, usually $\mathrm{C}_{16}$, to the porphyrin molecules. The photophysics of these molecules as they were attached to lipid sufaces could then be studied. Somewhat later, Ford used the same synthetic techniques to attach long alkyl chains to the commonly used photosensitizer ruthenium tris-bipyridine. Here, also, one or several alkyl chains could be attached. Ford studied the effect of solvent on the absorption and emission spectra 
of these derivatized ruthenium compounds. This was done in an effort to increase the portion of the solar spectrum that could be captured by shifting the absorption peaks of the sensitizer with this long-chain derivitization.

Step (2) -- Charge Separation Across a Phase Boundary and Step (3) Kinetic Stabiliztion of the Photoinduced Electron Transfer Products by a Mediator.

These two steps will be discussed together because they often overlap in practice. At solution-semiconductor interfaces the electron capture by the semiconductor electrode is irreversible because of the electric field produced in the semiconductor itself by the electrochemical gradient at the surface (band bending). In microheterogeneous systems there is electron transfer directly between the sensitizer and the mediator, which is present at the interface. In both cases, the end result is charge separation. Figure 1 illustrates the commonalities among the various kinds of interfaces that have been used for artificial photosynthesis and the possible ways of assembling them to achieve a complete, working system.

The first experiments on charge separation across a phase boundary were performed by Helmut Tributsch, a postdoctoral associate, and Calvin in 1970 and reported in Photochem. Photobiol. in 1971.1 They studied the electronic behavior of sensitized zinc oxide crystals, sensitized by adsorbed chlorophyll molecules, in a steady-state closed circuit in an electrochemical cell in which the sensitized photocurrent passes from electronic conduction in the semiconductor to ionic conduction in the electrolyte. This type of arrangement became the model for many semiconductor-sensitizer-solution combinations. (See "Bard-Fox", Section E, page 143.) 

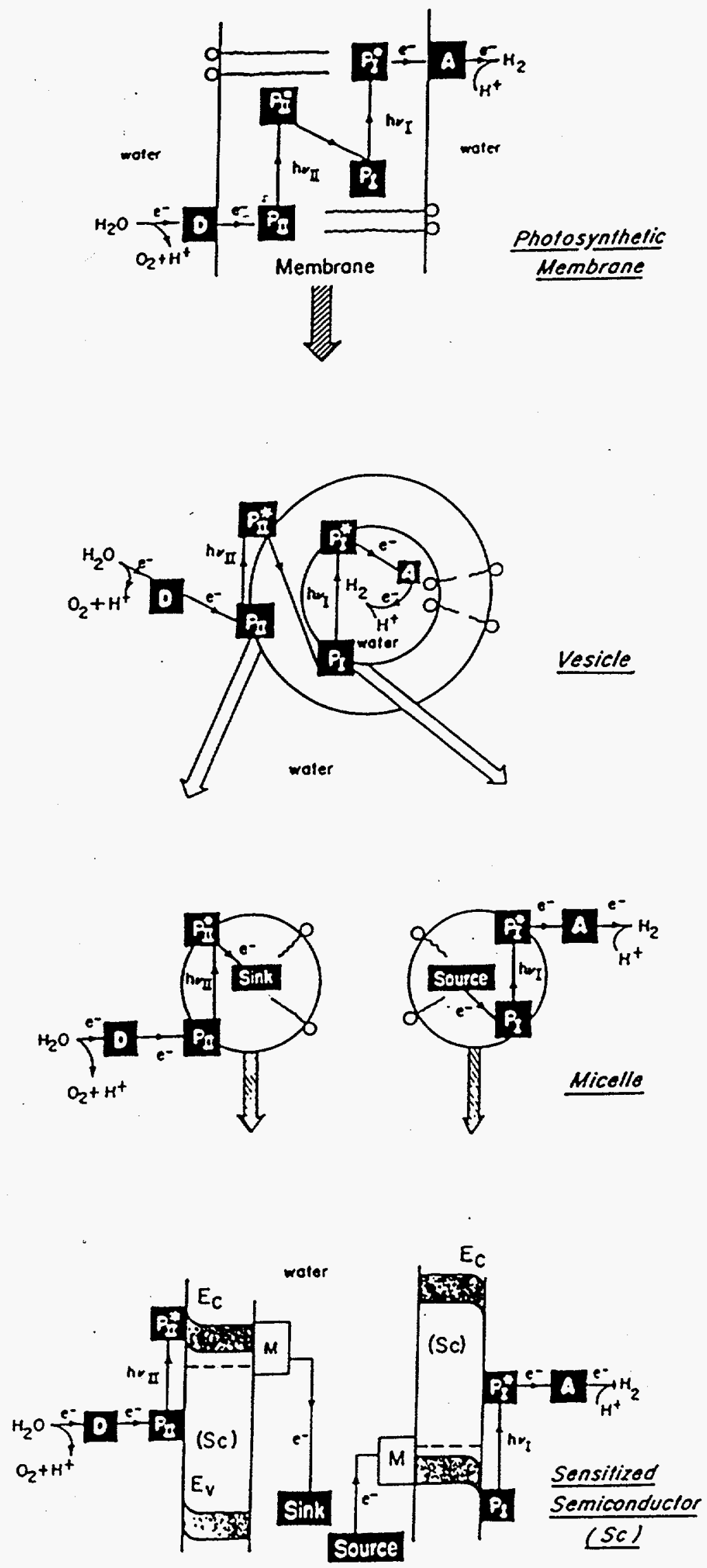

Figure 1. Photoelectron transfer scheme 
Later, in our own group, Mark Spitler ${ }^{6}$, a graduate student, studied the dynamics of electron transfer at $\mathrm{TiO}_{2}$ electrodes sensitized by rose bengal as well as the adsorption and oxidation of Rhodamine B at $\mathrm{Zn}$ electrodes. ${ }^{7}$ Such oxidation reactions produced by holes in the valence band degrade the sensitizer and have proved to be quite difficult to prevent. Two other graduate students, Terje Skotheim and Jer-MingYang, together with Melvin P. Klein, 33,34 studied the photochemical properties of sandwich cells in which there was no electrolyte solution. Rather, the sensitizer, mercocyanine in solid form, was pressed between a gold electrode and a semiconductor, $\mathrm{TiO}_{2}$. The photoelectric behavior of these cells could be modeled by assuming that the principal route for the formation of charge carriers was via single exciton diffusion through the merocyanine- $\mathrm{TiO}_{2}$ interface, followed by dissociation of the excitons into electron-hole pairs, electrons being injected into the $\mathrm{TiO}_{2}$ conduction band and holes into the merocyanine. The cells had a low fill factor that was attributed, in part, to the high series resistance of the undoped merocyanine films. Doping the merocyanine layer with iodine was found to increase the conductivity by as much as a factor of five. The overall quantum yield for a cell with a $500 \mathrm{~A}$ thick film was increased to $12 \%$, giving a monochromatic power efficiency of $0.4 \%$ at $520 \mathrm{~nm}$.

Most of the research at LBNL dealt with homogeneous and microheterogeneous systems (see "Bard-Fox", Section F, page 144) and included work with oil-water boundaries, lipid vesicles, colloidal $\mathrm{SiO}_{2}$ particles, polyelectrolytes, and latex particles. As a model for studying photosensitized charge transport across vesicle walls, we have used a membrane-bound tris(2,2'-bipyridyl)ruthenium(2+) derivative with two n-hexadecyl substituents (abbreviated to $\mathrm{Ru}^{2+}$ ) to mediate transfer of electrons from ethylenediaminetetraacetic acid (EDTA), dissolved in the encapsulated aqueous compartment of egg yolk phosphatidylcholine (PC) vesicles, to viologens dissolved in the continuous aqueous phase of the vesicle suspension. 
The vesicles were prepared in EDTA solution (as its ammonium salt) ( $\mathrm{pH} \mathrm{7),} \mathrm{by} \mathrm{the}$ injection technique, followed by gel filtration to replace the external EDTA solution with ammonium acetate solution containing $\mathrm{MV}^{2+}$ and $\mathrm{Zn}^{2+}$. We observed the production of $\mathrm{MV}^{+}$. upon illumination of the vesicle system with intervals of continuous visible light (Figure $2 ; \phi_{\max }=5 \times 10^{-5}$ ). The appearance of $\mathrm{MV}^{+} \cdot$, measured spectrophotometrically, had a sigmoidal dependence on the total amount of light absorbed by $\mathrm{Ru}^{2+}$, with saturation after about $10 \%$ of the $\mathrm{MV}^{2+}$ had been reduced. However, EDTA oxidation is irreversible and this reaction proceeds in homogeneous solutions photosensitized by $\mathrm{Ru}(\text { bipy })_{3}{ }^{2+}$ (Figure 2), so control experiments were required to insure that we were observing photosensitized electron transport across the vesicle walls. EDTA that was not removed by gel filtration, or that might have "escaped" from the vesicle interiors, was rendered inactive by adding an excess of zinc ions to the vesicle suspension after gel filtration. Figure 2 summarizes these experiments. Panels a) and b) illustrate the inactivation of EDTA by zinc ions in the aqueous phase. Comparison of panels a) and c) shows that the rate of electron transport through the vesicle walls is about 1/10 that of electron transfer in homogeneous solution. Panel d) proves that the compartmentalization of the reactants by the vesicle is essential. In the presence of detergent the vesicles are broken up and the PC homogenized.

Several other properties of the model vesicle system were determined in an interesting series of experiments. Ford ${ }^{15}$ studied the quantum yield of viologen radical production and found that it was dependent on the phospholipid-ruthenium mole ratio. The kinetics were inconsistent with a model in which diffusion of electron-transporting molecules is required for electron transport across the vesicle wall. Instead, the results pointed to electron exchange between $\mathrm{Ru}^{2+}$ and $\mathrm{Ru}^{3+}$ on opposite surfaces of the membrane. For charge balance, transport of protons (or other cations) must accompany the 


\section{PHOTO-INDUUCED ELECTRON TRANSFER ACROSS VESICLE WALLS}

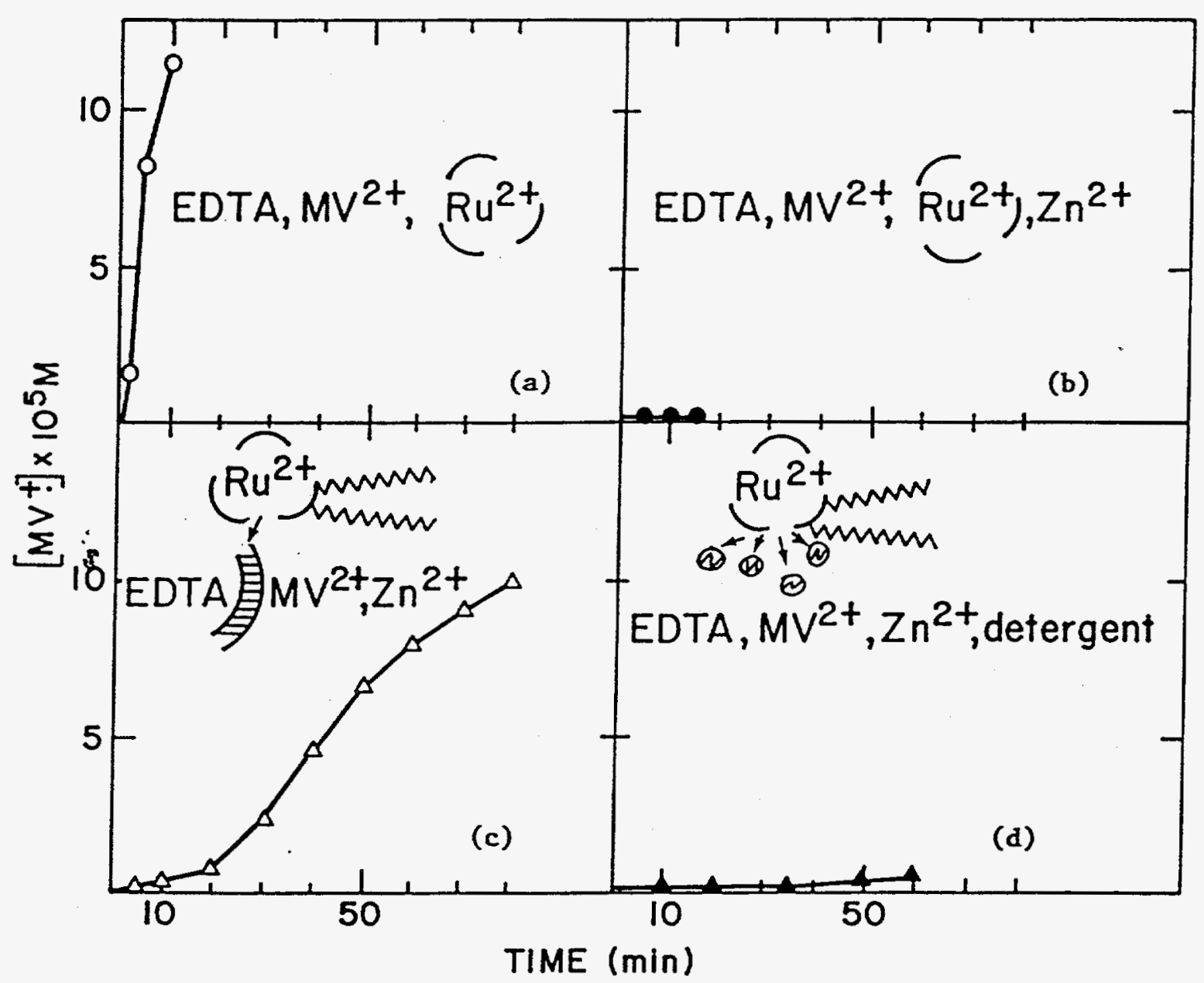

Figure 2. Photosensitized reduction of methylviologen in aqueous media using EDTA as electron donor and inhibition of the reaction by zinc ions
(a) Homogeneous conditions using $\mathrm{Ru}$ (bipy) $3^{2+}$ as sensitizer
(b) Composition as in (a) with zinc acetate added
(c) Vesicle dispersion with the amphiphilic analogue of $\mathrm{Ru}(\text { bipy })_{3}{ }^{2+}$
(d) Composition as in (c) but with detergent added 
electron exchange. The entire kinetic scheme is shown in Figure 3. The overall reaction rate is limited by the co-transport of cations.,

The scheme was further confirmed by Laane and Ford 22 with the use of ionophores such as valinomycin in the vesicle walls in the presence of $\mathrm{K}^{+}$. By aiding the cation transport, the valinomycin increased the quantum yield by a factor of more than 6 . The rate of electron transport across vesicle walls could be influenced further by the generation of transmembrane potentials with $\mathrm{K}^{+}$gradients in the presence of valinomycin. When vesicles are made with transmembrane potentials, interior more negative, the quantum yield of viologen reduction is doubled, and, conversely, when the interior is made more positive, the quantum yield is decreased and approaches the value found in the absence of valinomycin.

Finally, the temperature dependence of the photosensitized electron transport across vesicle walls was studied by Professor Howard Mettee, Ford, and Dr.T.Sakai, a visiting scientist .38 They were able to determine an overall Arrhenius activation energy of 117 $\mathrm{kJ} / \mathrm{mol}$. A value of $49 \mathrm{~kJ} / \mathrm{mol}$ is associated with the photosensitization process, while 67 $\mathrm{kJ} / \mathrm{mol}$ comes from the electron trransfer step. Only about $5 \mathrm{~kJ} / \mathrm{mol}$ of this latter energy is attributable to the co-transport of ions across the membrane. These numbers, again, are consistent with an electron transfer mechanism rather than one that involves diffusion across the membrane of the sensitizer molecule itself.

Another kind of interface that was extensively studied by postdoctoral fellows, Itamar Willner and Colja Laane, together with Yang 21,25,26,27 was that of colloidal silica particles in an aqueous suspension. The silanol groups on the particle surface are ionized at $\mathrm{pH}=6$ (see Figure 4). Consequently, the surface of the particle is negatively charged and a diffuse electrical double layer is produced in the vicinity of the solid interface. Because of 


$$
\begin{aligned}
& \text { B EDTA }\left|\quad{ }_{R u}^{2+}\right| C_{7} v^{2+} \frac{\frac{h \nu}{k_{0}}}{2 \times 10^{6} s^{-1}} \text { EDTA }\left|\quad R_{u}^{2+}\right| C_{7} v^{2+} A \\
& k_{1} \mid .13 \times 10^{6} \mathrm{~s}^{-1} \mathrm{k}_{2} / 15 \times 10^{6} \mathrm{~s}^{-1} \\
& \subseteq \text { EDTA }\left|\quad \mathrm{Ru}^{3+}\right| \mathrm{C}_{7} \mathrm{v}^{+} \\
& k_{-3}\left\{\|_{3} \quad .1 \times 10^{6} s^{-1}\right. \\
& \text { D EDTA }\left|\mathrm{Ru}^{3+}\right| \mathrm{C}_{7} \mathrm{~V}^{+} \\
& k_{4} \mid .6 \times 10^{6} \mathrm{~s}^{-1}
\end{aligned}
$$

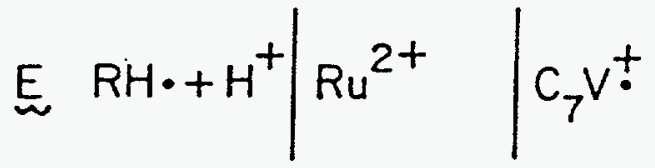

Figure 3. Kinetic model for photosensitized electron transport across vesicle wall, with estimated first-order rate constants. Vertical lines represent membrane-water interfaces. $\mathrm{RH} \cdot$ stands for EDTA less one hydrogen atom. 

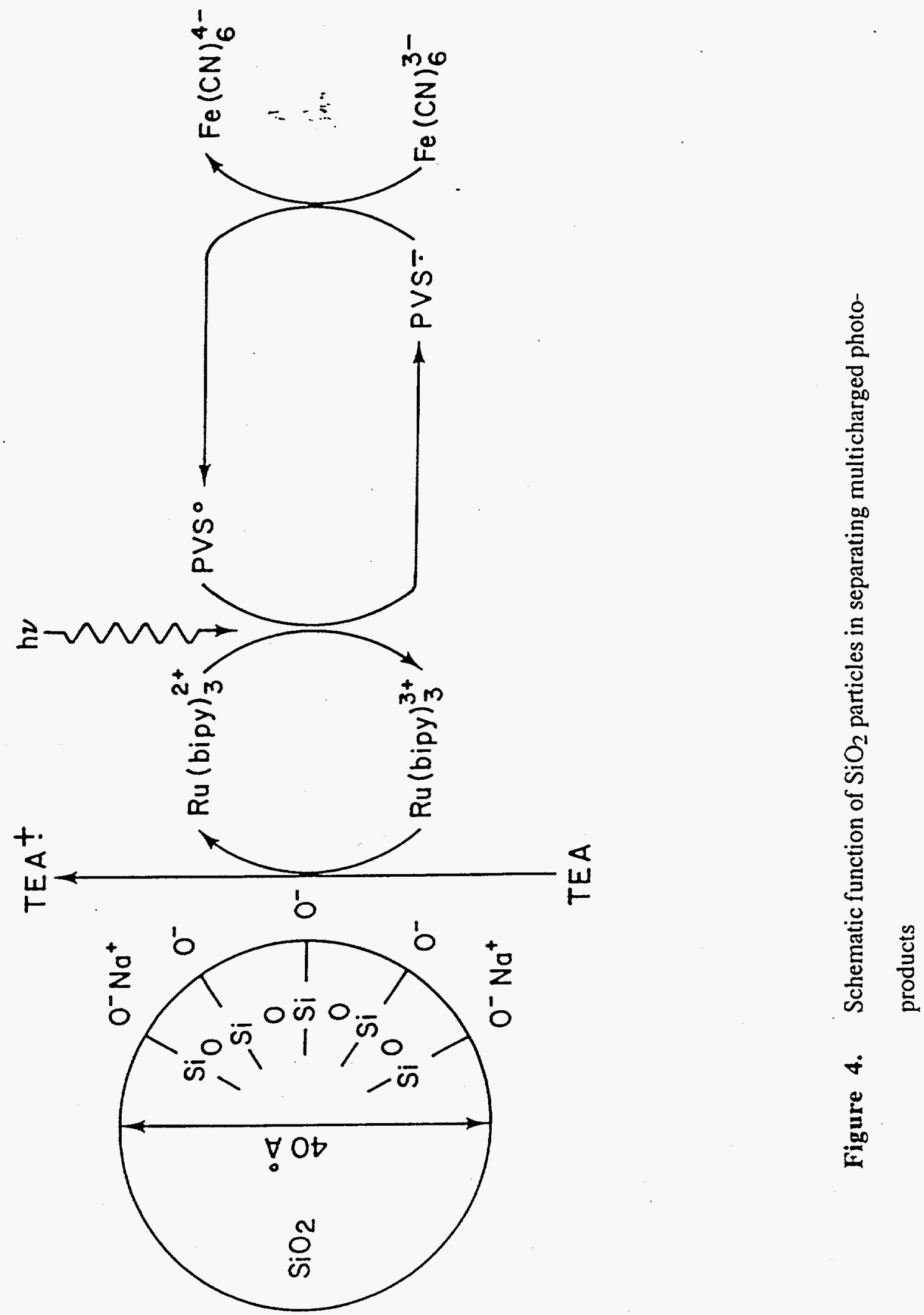

+
0
0 
the negative charges on the particles they repel one another and their agglomeration is prevented. The particles can be used to exert electrostatic repulsive and attractive interactions on the components involved in photosensitized reactions. By means of these interactions a component can be selectively adsorbed to the interface and its recombination with an oppositely charged photoproduct can be retarded.

To achieve such an organization in the system the different components have to be functionalized. Two positively charged sensitizers, $\mathrm{Ru}($ bipy $) 3^{2+}$ or zinc mesotetramethylpyridinium porphyrin ( $\left.\mathrm{ZnTMPYP}^{4+}\right)$, that are adsorbed to the $\mathrm{SiO}_{2}$ interface, are used. The zwitterionic dipropylsulfonate, 4,4'-bipyridinium 5 (propylviologen sulfonate, PVS ${ }^{\circ}$ ) is used as electron acceptor, and TEA is introduced as electron donor.

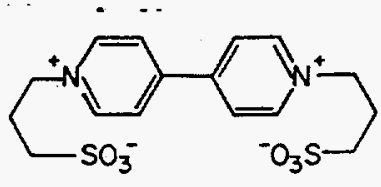

PVS

Photosensitized electron transfer in these systems results in a rapid production of the viologen radical PVS.-. The rates of PVS.- formation in the colloidal $\mathrm{SiO}_{2}$ systems using the different sensitizers are shown in Figure 5 and are compared with the analogous reactions in a homogeneous phase. It can be seen that the electron transfer reactions in the $\mathrm{SiO}_{2}$ colloid are enhanced about tenfold relative to the homogeneous phase, and using $\mathrm{ZnTMPyP} 4+$ as sensitizer a high quantum yield $(\phi=0.35)$ is obtained. The enhanced quantum yields in the $\mathrm{SiO}_{2}$ colloids are ascribed to the control of the electron transfer reaction by means of electrostatic interactions. The electron transfer from the excited sensitizer Ru(bipy) ${ }_{3}{ }^{2+}$ to the neutral electron acceptor results in two oppositely charged photoproducts. The charged interface interacts with these intermediate photoproducts; the oxidized sensitizer is adsorbed at the interface while the reduced negatively charged electron acceptor is repelled. Consequently, the electrostatic interactions introduce a barrier to the 


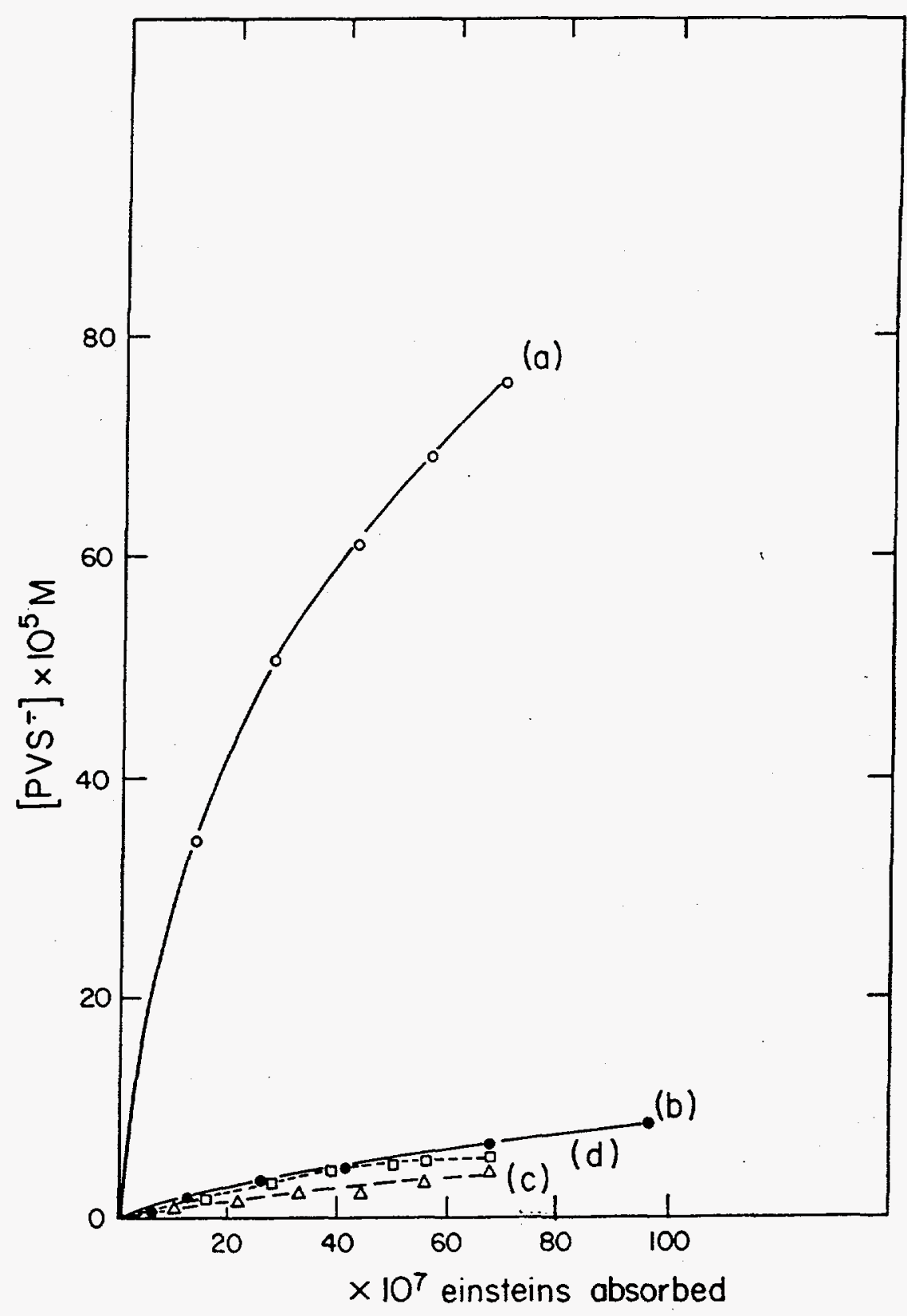

Figure 5. Propyl viologen radical (PVS- ${ }^{-}$) formation as a function of light absorbed

(a) $0.1 \% \mathrm{SiO}_{2}$ colloidal system, sensitizer $\mathrm{Zn}(\mathrm{TMPyP})^{4+}$

(b) Homogeneous aqueous solution, sensitizer Zn(TMPyP) $4+$

(c) $0.1 \% \mathrm{SiO}_{2}$ colloidal system, sensitizer $\mathrm{Zn}(\mathrm{TPPS})^{4}$

(d) Homogeneous aqueous solution, sensitizer $\mathrm{Zn}(\mathrm{TPPS})^{4-}$ 
degradative geminate recombination of the photoproducts. As a result, the further effective utilization of the oxidized product $\mathrm{Ru}(\text { bipy })_{3}{ }^{2+}$ in oxidizing the electron donor TEA is facilitated and high quantum yields are obtained.

As can be seen in Figure 5, the enhanced quantum yield is obtained only when the sensitizer has a positive charge and is held at the interface while the PVS- is repelled. With a negatively charged sensitizer the silica colloid has no effect. Moreover, it was found that an increase in ionic strength reduced the enhancing effect of the colloid, as would be expected if, indeed, electrostatic forces are playing a major role.

Several other interfaces were studied, but only briefly, to see how they might affect parts of the photoinduced electron transfer reaction. Arthur Frank ${ }^{12}$, a postdoctoral fellow, looked at the electron transfer quenching of rhodamine emission by various amines, both in homogeneous solution and in colloidal suspensions of latex particles. When the quenching took place on the latex surface there was a rate increase of almost two orders of magnitude. Using an emulsion of water in toluene Willner and Ford ${ }^{14}$ carried out the photosensitized reduction of a dye, 4-dimethylaminoazobenzene, present in the continuous toluene phase, by EDTA in the dispersed water phase. The reaction was photosensitized by $\mathrm{Ru}(\text { bipy })_{3}{ }^{2+}$ in the water droplets and mediated by benzylnicotinamide at the interface. The reaction was endoergic by about $9 \mathrm{~kJ}$ per mole of EDTA consumed, and thus represented a net storage of radiant energy. Thomas Casti ${ }^{4 l}$ a graduate student, used flash photolysis to study the effect of the surface of the polyelectrolyte, poly(styrene sulfonate) (PSS) on both the forward and reverse electron trransfer rates in the initial photosensitized reaction step. The sensitizer was zinc(II)tetrakis(4-Nmethylpyridinium) porphyrin ( $\mathrm{ZnP}$ ) while the electron acceptor was PVSo. Although the negatively-charged PSS strongly retarded the backreaction by a factor of about 60 , as expected by analogy to the $\mathrm{SiO}_{2}$ colloids studied 
earlier, flash photolysis results showed that it also retarded the forward reaction by roughly the same amount. Therefore, the overall quantum yield was not significantly improved. We ascribed this result to hydrophobic envelopment of the positively-charged porphyrin by the anionic polyelectrolyte. Thus, in this case, the polyelectrolyte is not merely an interface but rather it is behaving like a solvent for the sensitizer and therefore the interface model does not apply.

Step (4) -- Catalvtic Transformation of the Mediators to Final

\section{Oxidized and Reduced Products}

In Step (4) catalysts are needed on both sides of the assembly -- the reduction side as well as the oxidation side. The catalytic conversion of a reduced mediator to hydrogen has proved to be facile and has been accomplished with a number of catalysts such as metallic platinum and the enzyme, hydrogenase (see "Bard-Fox", p. 144). In our group we have concentrated on the more difficult oxidation side in trying to mimic the function of the manganese cluster in Photosystem II, in which molecular oxygen is produced from two molecules of water with the removal of four electrons:

$$
2 \mathrm{H}_{2} \mathrm{O} \longrightarrow \mathrm{O}_{2}+4 \mathrm{H}^{+}+4 \mathrm{e}^{-}
$$

To obtain the multiple charge-storing capacity that appears to be necessary to catalyze this reaction we have tried to use manganese and zinc porphyrins as well as di- $\mu$-oxo manganese compounds. The work on porphyrins was done by Professor Larry Spreer of the University of the Pacific together with Anthony Maliyackel 43,45,50,51 and Roland Wohlgemuth, postdoctoral fellows. 32,40 Professor Spreer was associated with our program for the last ten years and has made many other significant contributions as well. Rafael Rafaeloff, a visiting professor, and Janice Grant, a postdoctoral fellow, investigated 
the behavior of porphyrins in vesicle systems. ${ }^{46}$ The manganese di- $\mu$-oxo compounds were studied by Spreer, Karen Brewer and Richard Lumpkin, postdoctoral fellows, and Angele Liegeois, an undergraduate student. 52,53

While we had some success in identifying more than one oxidation state in some of these compounds, we discovered a di-iron derivative of a binucleating ligand that was shown by electrochemical experiments to exist in five oxidation states. Much of our most recent work was involved with optical and magnetic characterization of the di-iron compound and with studies of its chemistry. The compound contains iron atoms in two different macrocycles and the macrocycles are linked by a conjugated bridge. As isolated

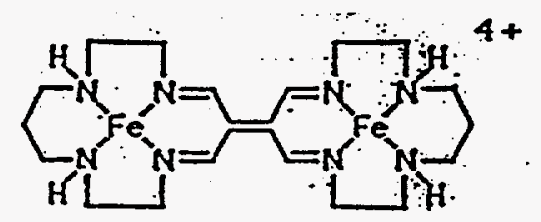

from acetonitrile it contains two low-spin iron(II) atoms with two axial acetonitrile ligands on each. The X-ray crystal structure of the parent di-iron compound was determined by Brewer, Spreer, and Scott Mountford, a graduate stuident. ${ }^{56}$ Its chemistry and physical properties were investigated by Spreer, and Brent MacQueen and Christopher Lange, postdoctoral fellows, and C. B. Allan, a graduate student. $58,59,60,61$

In rigorously dried acetonitrile we observe two reversible oxidations and two reversible reductions. This corresponds to five accessible oxidation levels for this compound. The oxidations involved the iron atom while the reductions presumably involve placement of electrons on the conjugated portion of the ligand. One-electron electrochemical oxidation of the $\left(\mathrm{Fe}^{2+} \mathrm{Fe}^{2+}\right.$ ) parent compound leads to an interesting mixed-valence, formally $\left(\mathrm{Fe}^{2+} \mathrm{Fe}^{3+}\right)$ species. Mixed-valence compounds are of fundamental interest to the inorganic chemist because of their intramolecular electron transfer, optical, and magnetic properties. Optical, electrochemical, and Mossbauer data 
indicate the mixed-valence compound with axial acetonitrile ligands is valence-delocalized even at $4.2 \mathrm{~K}$. This is the first such low-spin iron example in the literature. We have also made a mixed-valence compound with axial chloride ligands replacing the acetonitrile molecules. The data indicate that this complex is also valence-averaged.

Reactions of dioxyen with transition-metal complexes are numerous and varied. Of particular intrest are those reactions in which organic ligands are activated, because such reactions serve as models for enzymatic oxidation with cytochrome P-450. The dinuclear iron compound is readily attacked by dioxygen at atmospheric pressure and forms a ketone.
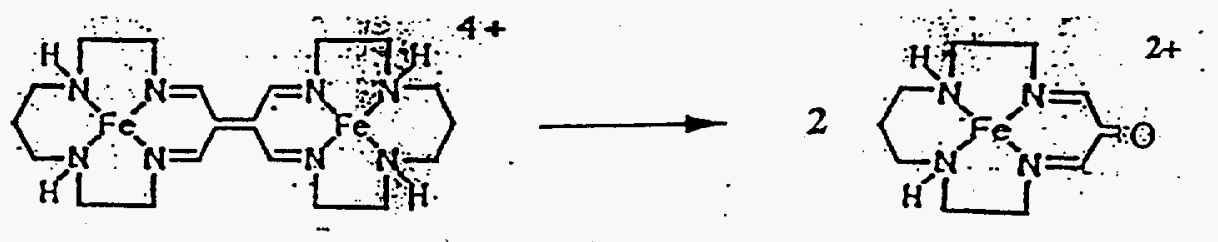

The identity of the ketone was established by its ${ }^{1} \mathrm{H}$ and ${ }^{13} \mathrm{C}$ magnetic resonance spectra. The proton spectrum for all ten hydrogens can be assigned. This means that the molecule is frozen into a single conformation on the NMR time-scale. An unusual aspect of the reaction of the dinuclear compound with dioxygen is that the rate is markedly affected by the solvent. The reaction to form the ketone in dimethyl formamide (DMF) is at least a factor of a thousand faster than in acetonitrile.

One of our highest priorities since our discovery of the unusual di-iron complex has been to extend the system to incorporate other metals into the binucleating ligand. We have now succeeded in making a di-ruthenium analogue with axial chloride ligands on the ruthenium atoms. 57 In the presence of oxygen we isolate the mixed-valence [formally $\left.\left(R u^{2}, R u^{3+}\right)\right]$ complex. We do not yet have an $\mathrm{X}$-ray crystal structure, but a good deal of evidence (mass spectral, optical, infrared, magnetic, and elemental analysis) indicates that the structure is similar to that of the di-iron compound. The ruthenium compound has a very intense, narrow, low-energy electronic transmission $\left(\lambda_{\max }=805 \mathrm{~nm}, \varepsilon=68,000 \mathrm{M}^{-}\right.$ ${ }^{1} \mathrm{~cm}^{-1} \gamma_{1 / 2}=1,100 \mathrm{~cm}^{-1}$ ). Such an intense, narrow absorption band in the NIR is most 
unusual for transition-metal complexes. We believe the mixed-valence complex is valenceaveraged $\left(\mathrm{Ru}^{2.5}, \mathrm{Ru}^{2.5+}\right)$ and the NIR band is due to a transition from this delocalized ground state to an excited state.

The mixed-valence compound has a very large $\Delta E$ for successive oxidations from the $\left(\mathrm{Ru}^{2+}, \mathrm{Ru}^{2+}\right)$ to $\left(\mathrm{Ru}^{2+}, \mathrm{Ru}^{3+}\right)$ and then to the $\left(\mathrm{Ru}^{3+}, \mathrm{Ru}^{3+}\right)$ level. This leads to the impressively large $\mathrm{K}_{\mathrm{com}}$ of $3.5 \times 10^{15}$ for the equilibrium:

$$
\left(\mathrm{Ru}^{2+}, \mathrm{Ru}^{2+}\right)+\left(\mathrm{Ru}^{3+}, \mathrm{Ru}^{3+}\right)=2\left(\mathrm{Ru}^{2+}, \mathrm{Ru}^{3+}\right)
$$

This is the largest $K_{\text {com }}$ in the mixed-valence transition metal literature that we are aware of and certainly supports our assignment of the complex as a resonance-stabilized . $\left(\mathrm{Ru}^{2.5+}, \mathrm{Ru}{ }^{2.5+}\right)$.

As mentioned above, our main interest in the di-iron complex is its possible use as a multiple-electron oxidation catalyst. We are now examining a very unusual reaction that occurs in acetonitrile that contains a small amount of water. The second oxidation in rigorously dried acetonitrile apparently produces the iso-valent $\left(\mathrm{Fe}^{3+}, \mathrm{Fe}^{3+}\right)$ ion. However, the features of this second oxidation wave are greatly influenced by the presence of water. If a small amount of water is present, the anodic current at the higher potential increases significantly and a new cathodic wave appears. These results suggest an oxidative process that involves water and is catalytic, since the peaks associated with the di-iron complex do not disappear.

We have done bulk electrolysis experiments in which 30-40 electrons per dinuclear complex molecule have been passed. In these experiments a large concentration (10 millimolar) of the new redox species can be obtained. It has not yet been identified, but 
we are not aware in the literature of any transition-metal catalyzed oxidative process involving $\mathrm{CH}_{3} \mathrm{CN}$ and water.

It is apparently possible to incorporate still other metals into the macrocycle. In another laboratory, a di-nickel complex of the binucleating ligand has been reported [McCauley and Yu, Inorg. Chem. 31, 5549 (1992)]. Some very interesting comparisons between the different bimetallic complexes of this same ligand are already possible. For

example, the reduction processes in all cases are presumed to involve placing electrons on the ligand. What is unusual is the large difference between the reduction potentials. In acetonitrile the di-nickel is reduced at $+0.60 \mathrm{~V}$, the di-iron at $-0.18 \mathrm{~V}$, the di-ruthenium at $-0.90 \mathrm{~V}$ (vs NHE). This large dependence of the reduction potential on the metal is in contrast to metalloporphyrin systems. This suggests extensive mixing of metal and ligand orbitals in the new cross-conjugated binucleating ligand.

Because of the apprently rich chemistry of these bis-marocyclic compounds, it should be possible, by exploring the available modifications, to fine-tune the properties of our potential oxidation catalysts to their role in artificial photosynthesis.

\section{Photochemical Reduction of Carbon Dioxide}

Although we usually consider artificial photosynthesis to be a process that splits water into oxygen and hydrogen (a fuel), a broader definition would include the use of visible light to drive other thermodynamically uphill reactions of abundant materials, such as $\mathrm{CO}_{2}$, to produce fuels such as $\mathrm{CO}$ and other reduced products. During the late 1980 's, Spreer together with Grant, Brewer,Kisholoy Goswami and Carl Craig, postdoctoral fellows, and Scott Taylor, a staff scientist, examined the photochemical reduction of 
carbon dioxide using nickel tetraazamacrocycles as catalysts. 49,55 The two most studied were 12-aneN $4(1,4,7,10$-tetraazacyclododecane $)$ and 14-aneN $4(1,4,8,11$-tetraazacyclotetradecane) and the crystal structure of the former was determined. ${ }^{54}$ The photochemical reduction of carbon dioxide occurs in homogeneous solution of $\left[\mathrm{Ru}(\mathrm{bpy})_{3}\right]^{2+}$ as a photosensitizer, with narrow band illumination at $440 \mathrm{~nm}$, and the chlorides of $\mathrm{Ni}(\mathrm{II})$ tetraazamacrocycles as electron transfer catalysts. The medium is an aqueoous, $\mathrm{CO}_{2-}$ saturated, buffered solution where ascorbate is both a buffer and a sacrificial electron donor. We have established, using radiotracer techniques, that $\mathrm{CO}_{2}$ is the sole source of carbon in the product, carbon monoxide. In addition, ${ }^{14} \mathrm{C}$ labeling experiments showed that no additional species were formed in solution (e.g. formate or methanol) concomitant with $\mathrm{CO}$ production. Therefore, we were able to establish the overall quantum yield for $\mathrm{CO}_{2}$ reduction in this photoredox system. The quantum yield for $\mathrm{CO}$ production using

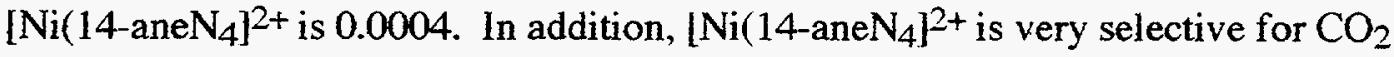
reduction versus water reduction. The quantum yield for hydrogen production when $\left[\mathrm{Ni}\left(14-\mathrm{aneN}_{4}\right)\right]^{2+}$ is used as a reduction catalyst is less than $1 \times 10^{-5}$.

We have also prepared a second $\mathrm{Ni}$ (II) tetraazamacrocycle, 1,4,7,10-tetraazacyclodododecane $\mathrm{Ni}(\mathrm{II})$ triflate, $\left[\mathrm{Ni}\left(12-\mathrm{aneN}_{4}\right)\right]\left(\mathrm{CF}_{3} \mathrm{SO}_{3}\right)_{2}$ for study in our photoredox system. This complex differs only slightly in empirical formula from the chloride; however, the chemical and physical properties of the two Ni(II) complexes differ significantly. The structure of [ $\mathrm{Ni}\left(14-\mathrm{aneN}_{4}\right] \mathrm{Cl}$ is pseudo octahedral with the chloride ions bound trans
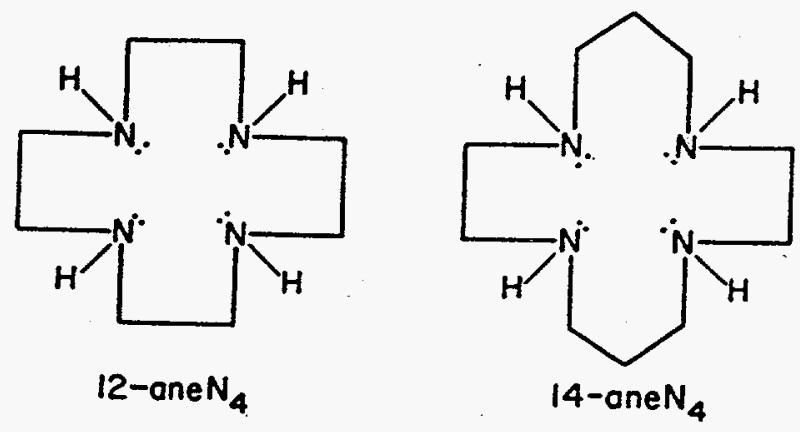
to one another. The structure of $\left.\left[\mathrm{Ni}\left(12-\mathrm{aneN}_{4}\right)\right)\right]\left(\mathrm{CF}_{3} \mathrm{SO}_{3}\right)_{2}$ has only two of the coordinated nitrogens bound trans to one another, formally leaving two adjacent or cis coordination sites unoccupied. It is likely that $\left[\mathrm{Ni}\left(12-\mathrm{aneN}_{4}\right)\right]^{2+}$, having cis oriented vacancies in the coordination sphere (as opposed to the trans vacancies for $\left.\left[\mathrm{Ni}\left(14 \text {-ane } \mathrm{N}_{4}\right)\right]^{2+}\right)$ contributes to the mode of $\mathrm{CO}_{2}$-nickel binding and perhaps ultimately to the type of photoproducts the catalyst can generate. $[\mathrm{Ni}(12 \text {-aneN } 4)]^{2+}$ reduces $\mathrm{CO}_{2}$ to $\mathrm{CO}$ with a quantum efficiency approaching that of our previous catalyst. The quantum yield for $\mathrm{CO}$ production is 0.0003 . Again, $\mathrm{CO}_{2}$ has been identified as the only source of carbon for $\mathrm{CO}$; however, in addition to carbon monoxide, we have found that $\left[\mathrm{Ni}\left(12 \text {-ane } \mathrm{N}_{4}\right)\right]^{2+}$ also produces formate as a two-electron reduction product of $\mathrm{CO}_{2}$. The quantum yield for formate production is comparable to the quantum yield for $\mathrm{CO}$ production. By manipulating the coordination geometries of the nickel catalysts it may be possible to control photoproduct selectivity as well as enhance the overall quantum yield of carbon dioxide reduction.

The quantum efficiencies given above are quite low. This is not surprising since the proposed mechanism for the reaction involves many steps, including the formation of a $\mathrm{Ni}-\mathrm{H}$ complex, carbon dioxide insertion, and a bimolecular electron transfer reaction.

Earlier electrochemical results had shown that the $[\mathrm{Ni}(14 \text {-aneN } 4)]^{2+}$ complex is a remarkably efficient catalyst for the electroreduction of $\mathrm{CO}_{2}$. The electrochemical results are best explained by adsorbed species on the electrode surface. The fact that $\left[\mathrm{Ni}\left(14-\mathrm{aneN} \mathrm{N}_{4}\right)\right]^{2+}$ is a much better electrocatalyst than any other $\mathrm{Ni}(\mathrm{II})$ complex has been attributed to is planar nature which presumably facilitates adsorption and subsequent access of the $\mathrm{CO}_{2}$ substrate to the nickel center. In contrast, the 14 and 12 -membered macrocyclic nickel complexes are quite similar in their ability to reduce $\mathrm{O}_{2}$ in our homogeneous system. The $\left[\mathrm{Ni}\left(14-\mathrm{aneN}_{4}\right)\right]^{2+}$ species is very selective in the 
electrochemical system in favoring $\mathrm{CO}_{2}$ reduction over water reduction. Moreover, in our photoredox system the 12-member as well as the 14-member macrocyclic nickel complex reduces $\mathrm{CO}_{2}$ with $\mathrm{H}_{2}$ only a very minor product.

\section{Prospects for the Future}

(See also last section of the Bard-Fox article, page 145).

For the ultimate success of an artificial photosynthetic energy storage system advancement must be made along several lines.

(1) The useful fraction of the total spectral irradiance must be increased. At present, with resonance absorbers like dyes and other chromophores, only narrow spectral regions are useful; with band-gap substances, such as semiconductors, broader regions are absorbed, but the excess energy over the band-gap is converted to heat and lost to the storage system. It is obvious that a series of relatively narrow-band sensitizers could be arranged to take advantage of the full solar spectrum. So far, there has not been much attention paid to this area because mostly it has been simplified, model systems that have been studied. But once the follow-on steps after initial absorption have been improved and perfected, it is clear that widening the usable spectral band will give immediate increases in overail efficiency.

(2) The quantum yield of the initial photochemical storage reaction must be improved. This has been our main thrust over the years. In addition to making improvements in the separation and compartmentalization of the initial photoreaction products, we must increase 
our application of flash photolysis and other kinetic techniques to unravel the reaction mechanisms further so that we can find the steps that limit quantum yield.

(3) The free energy stored per mole of reaction products must be increased. Research on artificial photosynthesis has been concerned mainly with demonstrating principles, and we have utilized substrates and reactions where energy storage per se was not the primary consideration. But eventually a photochemical cycle must be perfected that produces oxygen, on the one hand, and hydrogen, or other energy-rich materials, on the other. It is also possible that the oxidizing power of the intermediate can be used to produce peroxides and other useful products. Although not a great deal of research has yet been done on it, the photochemical reduction of carbon dioxide is another attempt at developing a photochemical reaction in which a large fraction of the photon energy is stored.

While solutions to the problems discussed above are necessary for completion of a practical artificial photosynthesis assembly, they are by no means sufficient. Since our work has dealt mainly with principles and basic research, we have not addressed the issues of stability and ruggedness of the components. Nor have the many others who have been active in the field, and for good reason. Until the chemistry and photophysics have been worked out, it makes no sense to begin optimizing the durability of the materials of construction. But in the end these questions will become the dominant ones. (See BardFox, Section B, page 142). It may be that materials science and engineering breakthroughs will be needed before artificial photosynthesis can mature.

\footnotetext{
Acknowledgment. Wc are grateful to Marilyn Taylor for her help with the historical information, the indexing, and the general assembly of this report. The preparation of the report was supported in part by the Director, Office of Energy Research, Office of Basic Encrgy Scicnces, Chemical Sciences Division, U.S. Department of Energy under Contract No.DE-AC03-76SF00098.
} 


\title{
APPENDIX I
}

\author{
Allen J. Bard and Marye Anne Fox \\ Artificial Photosynthesis: Splitting of Water to \\ Hydrogen and Oxygen
}

Accounts of Chemical Research (1995) 28, 141-145

Reprinted with permission from Acc. Chem.Res. 199528 141-145. Copyright 1995 American Chemical Society 
Reprinted with permission from Acc. Chem. Res. 1995, 28, 141-145.

Copyright 1995

American Chemical Society

\title{
Artificial Photosynthesis: Solar Splitting of Water to Hydrogen and Oxygen
}

\author{
Allen J. BARD* AND MARYE ANNE FoX* \\ Department of Chemistry and Biochemistry, University of Texas at Austin, Austin, Texas 78712 \\ Received November 16, 1994
}

\section{Water Splitting}

The maintenance of life on earth, our food, oxygen, and fossil fuels depend upon the conversion of solar energy into chemical energy by biological photosynthesis carried out by green plants and photosynthetic bacteria. In this process sunlight and available abundant raw materials (water, carbon dioxide) are converted to oxygen and the reduced organic species that serve as food and fuel. A long-standing challenge has been the development of a practical artificial photosynthetic system that can roughly mimic the biological one, not by duplicating the self-organization and reproduction of the biological system nor the aesthetic beauty of trees and plants, but rather by being able to use sunlight to drive a thermodynamically uphill reaction of an abundant materials to produce a fuel. In this Account we focus on "water splitting", the photodriven conversion of liquid water to gaseous hydrogen and oxygen:

$$
\mathrm{H}_{2} \mathrm{O}(\mathrm{l}) \stackrel{\text { sunlight }}{\longrightarrow} \mathrm{H}_{2}(\mathrm{~g}, 1 \mathrm{~atm})+1 / 2 \mathrm{O}_{2}(\mathrm{~g}, 1 \mathrm{~atm})
$$

Beyond the intellectual challenge of designing and fabricating such a system, there are several practical implications. $\mathrm{H}_{2}$ could serve directly as a fuel, e.g., for transportation or for the production of electricity in fuel cells, without producing pollutants or greenhouse gases upon combustion. For some purposes, however, it might be useful to use the $\mathrm{H}_{2}$ as a reactant to produce a different fuel, such as one that is liquid at the usual temperatures and pressures. Thus, we seek as a "Holy Grail" a renewable energy source driven by solar energy that produces a clean and storable fuel.

Let us define this Holy Grail more specifically. We want an efficient and long-lived system for splitting water to $\mathrm{H}_{2}$ and $\mathrm{O}_{2}$ with light in the terrestrial (AM1.5) solar spectrum at an intensity of one sun. For a practical system, an energy efficiency of at least $10 \%$ appears to be necessary. This means that the $\mathrm{H}_{2}$ and $\mathrm{O}_{2}$ produced in the system have a fuel value of at least $10 \%$ of the solar energy incident on the system. In the southern United States, the instantaneous maximum intensity is of the order of $1 \mathrm{~kW} / \mathrm{m}^{2}$ and the average 24-h intensity throughout a year is about 250 $\mathrm{W} / \mathrm{m}^{2}$. Thus, the system should produce $\mathrm{H}_{2}$ at a rate of about $0.7 \mathrm{~g} / \mathrm{s}$ or $7.8 \mathrm{~L}(\mathrm{STP}) / \mathrm{s}$ per $\mathrm{m}^{2}$ of collector at maximum solar intensity. Long-lived implies that the

Allen J. Bard holds the Hackerman-Welch Regents Chair in Chemistry at The University of Texas and works on the application of electrochemical methods to chemical problems.

Marye Anne Fox currently occupies the $M$. June and J. Virgil Waggoner Regents Chair in Chemistry at the University of Texas and is director of the Center for Fast Kinetics Research. Her principal research interests are in physical organic chemistry. sensitizers and catalysts, as well as the materials of construction, will not be consumed or degraded under irradiation for at least 10 years. The solar spectrum at sea level extends from the near infrared through the visible to the near ultraviolet with photon energies up to $3.0 \mathrm{eV}$. This region is not absorbed by water itself, so photochemical reactions are only possible in the presence of some recyclable absorbing sensitizer. Finally, for practical applications, the cost of $\mathrm{H}_{2}$ produced by the system (on an energy equivalent basis) should be competitive with that of fossil fuels.

Although we have defined our Holy Grail in terms of the water-splitting reaction, other chemical solar energy conversions are possible and have been investigated. For example, there are semiconductor liquid junction systems that, when irradiated with visible light, carry out the reactions $2 \mathrm{HBr} \rightarrow \mathrm{H}_{2}+\mathrm{Br}_{2}$ and $2 \mathrm{HI} \rightarrow \mathrm{H}_{2}+\mathrm{I}_{2}$. Indeed, the "brine splitting" or "photochloralkali" reaction,

$$
2 \mathrm{H}_{2} \mathrm{O}+2 \mathrm{Cl}^{-} \stackrel{h \mathrm{r}}{\longrightarrow} 2 \mathrm{OH}^{-}+\mathrm{Cl}_{2}+\mathrm{H}_{2}
$$

would probably be more useful than water splitting, but has so far not been achieved without applying an additional external potential.

Many investigations in this field have involved sacrificial donors, which are reduced materials that are oxidized more easily than water, for example, ethylenediamine tetraacetic acid or triethanolamine. The use of such compounds usually greatly improves the efficiency of the solar process, but clearly is not of interest in practical systems, especially if the sacrificial donors are more expensive than the $\mathrm{H}_{2}$ produced. It might be possible to use reduced waste materials in this role, but is it unlikely that this approach will be practical in large-scale fuel production.

Photoelectrochemical approaches may be useful, however, as a means of water treatment, destroying organic wastes and removing metals. There are also a number of chemical schemes for converting solar energy to electrical energy, e.g., in liquid junction photovoltaic cells. Indeed, devices with single-crystal semiconductors have been constructed which show solar efficiencies of above $10 \%$. It remains to be seen whether such chemical photovoltaic systems will be practically competitive with solid state ones based, for example, on single-crystal or amorphous $\mathrm{Si}$. Although many of these alternative chemical solar energy systems are interesting, we focus here on the watersplitting reaction, because it effectively represents the scientific challenges typical of all such efforts.

\section{History and Progress}

A. Efficiency. The free energy change for reaction 1 is $\Delta G^{\circ}=237.2 \mathrm{~kJ} / \mathrm{mol}$ or $2.46 \mathrm{eV} /$ molecule of $\mathrm{H}_{2} \mathrm{O}$. 
Since two electrons are involved in the reaction as written $(n=2)$, this corresponds to $1.23 \mathrm{eV} / \mathrm{e}$, which is also the standard emf for the reaction. The photons in the solar spectrum provide sufficient energy to drive this reaction, but the efficiency of the reaction depends upon how the reaction is carried out. It is possible to cause water splitting thermally with light via concentrators and a solar furnace by heating water to 1500 $2500 \mathrm{~K} .1$ However, the efficiency of this process is typically below $2 \%$, and the cost of the capital equipment and material stability problems suggest that this approach to solar water splitting is not a promising one.

Since water itself does not absorb appreciable radiation within the solar spectrum, one or more lightabsorbing species (photoconverters or sensitizers) must be used to transduce the radiant energy to chemical (or electrical) energy in the form of electron hole pairs, i.e., to the oxidizing and reducing potential needed to drive the reaction. The maximum efficiency for photochemical solar converters has been considered in a number of papers ${ }^{2}$ and depends upon the band gap (or threshold energy), $E_{\mathrm{g}}$, of the photoconverter. Radiation of energy below $E_{\mathrm{g}}$ is not absorbed while that above $E_{\mathrm{g}}$ is partly lost as heat by internal conversion or intraband thermalization processes. Additional thermodynamic losses occur because the excited state concentration is only a fraction of that of the ground state and because some excited states are lost through radiative decay. ${ }^{2}$ When these factors are taken into account, the threshold photon energy and the maximum efficiency can be calculated. For a single photoconverter system, wavelengths below 770 $\mathrm{nm}$ (or energies above $1.6 \mathrm{eV}$ ) are required to yield a maximum efficiency of about $30 \%$. Lower photon energies and higher efficiencies are attainable if one employs two photoconverters. Thus for a system with two photoconverters with two different, optimized $E_{g}$ values, one finds a maximum solar efficiency of $41 \%{ }^{2}$ These calculations show that, in principle, the desired efficiency for water splitting is attainable, even with a system involving a single photoconverter.

B. Semiconductor Solid State PhotovoltaicBased Systems. A number of different approaches are possible with semiconductors as the photoconverter. The most direct, brute force, approach employs a solid state photovoltaic solar cell to generate electricity that is then passed into a commercial-type water electrolyzer (Figure 1A). The maximum theoretical efficiency for a $\mathrm{Si}$ photovoltaic cell is $33 \%$, and the efficiencies of the best laboratory cells have been reported to be about 24\%. Commercial single-crystal $\mathrm{Si}$ solar cells generally have efficiencies in the 12$16 \%$ range. The electrolysis of water at a reasonable rate in a practical cell requires applied voltages significantly larger than the theoretical value $(1.23 \mathrm{~V}$ at $25^{\circ} \mathrm{C}$ ), and electrolysis energy efficiencies of about $60 \%$ are typical. Thus, the efficiency of the combined solar/electrolyzer system using commercially available components is close to the desired $10 \%$ defined for solar hydrogen generation. Moreover, the components are rugged and should be long-lived. The problem with such a system is its cost. Solar photovoltaics cannot currently produce electricity at competitive

(1) Etiévant, C. Solar Energy Mater. 1991, 24, 413.

(2) Archer, M. D.: Bolton, J. R. J. Phys. Chem. 1990, 94, 8028 and references therein.

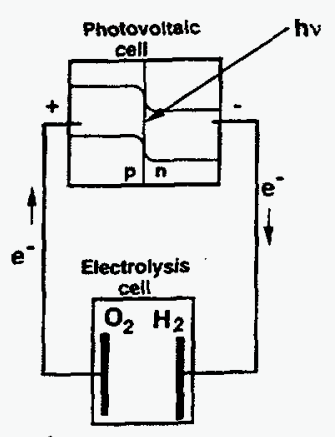

A

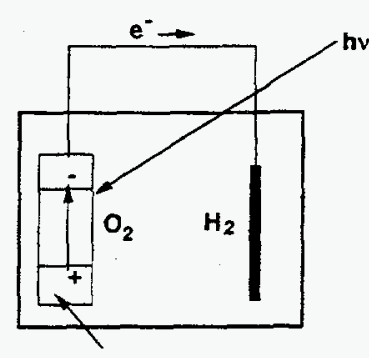

n-type semiconductor

c

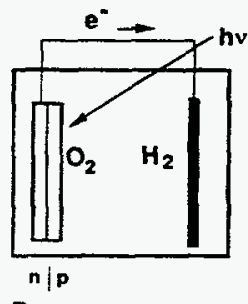

B
Figure 1. Schematic diagrams of different types of semiconductor-based systems proposed for solar water splitting: (A) solid state photovoltaic cell driving a water electrolyzer; (B) cell with immersed semiconductor $\mathrm{p} / \mathrm{n}$ junction (or metal/semiconductor Schottky junction) as one electrode; (C) liquid junction semiconductor electrode cell; (D) cell with dye-sensitized semiconductor electrode.

prices, and hydrogen from water electrolyzers is significantly more expensive than that produced chemically from coal or natural gas. Lower cost solar cells are possible, e.g., through the use of polycrystalline or amorphous Si or other semiconductors (CdS, CdTe, $\mathrm{CuInSe}_{2}$ ), and some improvements in water electrolyzer efficiency through better configurations and catalysts and the use of higher temperatures are possible. However, it probably will be difficult to bring the overall cost down to levels that make such a configuration practical in the foreseeable future.

An alternative system involves the semiconductor photovoltaic cell immersed directly in the aqueous system (Figure 1B). At the least this eliminates the costs and mechanical difficulties associated with separate construction and interconnection of solar and electrochemical cells. In one such system, the electrodes are composed of single or multiple semiconductor $\mathrm{p} / \mathrm{n}$ junctions that are irradiated while they are within the cell. This simpler apparatus is attained at the cost of encapsulating and coating the semiconductors to protect them from the liquid environment and probably with a more limited choice of electrocatalyst for $\mathrm{O}_{2}$ or $\mathrm{H}_{2}$ evolution. Moreover, the opencircuit photovoltage of a single $\mathrm{Si} / \mathrm{p} / \mathrm{n}$ junction is only $0.55 \mathrm{~V}$, so at least three of these in series would be needed to generate the necessary potential for water splitting. For example, in a system developed at Texas Instruments ${ }^{3}$ (TI) $\mathrm{p}-\mathrm{Si} / \mathrm{n}$-Si junctions were produced on small ( $0.2 \mathrm{~mm}$ diameter) Si spheres embedded in glass and backed by a conductive layer to form an

(3) Kilby, J. S.; Lathrop, J. W. Porter, W. A. U.S. Patent 4021323 , 1977; U.S. Patent 4100051,1978 ; U.S. Patent 4136436,1979 . See also: Johnson. E. L. In Electrochemistry in Industry; Landau, U., Yeager, E., Kortan, D., Eds.; Plenum: New York, 1982; pp 299-306. 
array. Each sphere behaved as a photovoltaic cell and produced about $0.55 \mathrm{~V}$. The use of two arrays, protected with noble metal catalysts $(\mathrm{M})$, i.e., $\mathrm{M} / \mathrm{p}-\mathrm{Si} /$ $\mathrm{n}-\mathrm{Si}$ and $\mathrm{M} / \mathrm{n}-\mathrm{Si} / \mathrm{p}-\mathrm{Si}$, connected in series and in contact with $\mathrm{HBr}$, allowed $\mathrm{H}_{2}$ and $\mathrm{Br}_{2}$ to be generated with about an $8 \%$ efficiency. Multiple TI photoarray cells to carry out water splitting and other reactions requiring higher potentials are possible ${ }^{4}$ at a considerable sacrifice in efficiency. Note that, in addition to $\mathrm{p} / \mathrm{n}$ semiconductor junctions, those between a metal and semiconductor (Schottky barriers) can be used to produce a photopotential, e.g., in electrodes such as $\mathrm{Au} / \mathrm{n}-\mathrm{GaP}, \mathrm{PtSi} / \mathrm{n}-\mathrm{Si}$, and Pt/n-GaAs.

C. Semiconductor Electrode (Liquid Junction) Systems. Of more interest to chemists are systems in which the photopotential to drive the water-splitting reaction is generated directly at the semiconductor/liquid interface (Figure 1C). In 1839 Becquerel noted small photoeffects when metal electrodes were irradiated in electrochemical cells. ${ }^{5}$ Rather extensive research was carried out on various metal electrodes, sometimes covered with oxide or other films, and immersed in a variety of solutions, including some containing fluorescent dyes. ${ }^{6}$ The effects seen were usually small, and given the state of electrochemistry and knowledge of the electronic properties of solids, the results were generally poorly understood. The discovery of the transistor and interest by chemists and physicists in semiconductor materials, notably $\mathrm{Si}$ and $\mathrm{Ge}$, led to more extensive electrochemical and photoelectrochemical studies, usually with the goal of characterizing the semiconductor. 7,8

The modern era of semiconductor electrodes and interest in these in photoelectrochemical devices for energy conversion, especially via the water-splitting reaction, can be traced to the work of Honda and Fujishima on single-crystal $\mathrm{TiO}_{2}$ electrodes. ${ }^{9}$ Indeed, water splitting in $\mathrm{TiO}_{2}$-based cells can be accomplished, but only with an additional electrical bias. The problem with $\mathrm{TiO}_{2}$ is that the conduction band is too low (i.e., at an insufficiently negative potential) to generate hydrogen at a useful rate. Moreover, because the $\mathrm{TiO}_{2}$ band gap is large ( $3.0 \mathrm{eV}$ for rutile), only a small fraction of the solar light is absorbed and the efficiency of $\mathrm{TiO}_{2}$-based cells can never attain the specified $10 \%$ level. Cells with $\mathrm{TiO}_{2}$ electrodes of various types (e.g., single crystal, polycrystalline, thin film) have nevertheless been heavily investigated, largely because $\mathrm{TiO}_{2}$ is very stable and is a good model for understanding the semiconductor/liquid interface.

The stability of the semiconductor in contact with a liquid and under irradiation is an important factor. To generate oxygen, rather energetic photogenerated holes are required, and these tend to cause decomposition of the semiconductor. Thus, a key requirement in cells of this type, involving a single photojunction, is the discovery of a semiconductor with an appropriate band gap (< about $2.5 \mathrm{eV}$ ), with the conduction

(4) White, J. R.; Fan, F.R. F.; Bard, A. J. J. Electrochem. Soc. 1985, 132,544 .

(5) Becquerel, E. C. R. Hebd. Seances Acad. Sci. 1839, 9, 561

(6) Copeland, A. W.; Black, O. D.; Garrett, A. B. Chem. Rev. 1942, 31,177 .

(7) Gerischer, $H$. In Advances in Electrochemistry and Electrochemical Engineering; Delahay, P., Ed.; Interscience Publishers: New York, 1961; Vol. $1, \mathrm{p} 139$.

(8) Myamlin, V. A.; Pleskov, Yu. V. Electrochemistry of Semiconduc tors; Plenum Press: New York, 1967.

(9) Fujishima, A.; Honda, K. Nature 1972, 238, 37 band sufficiently negative for hydrogen evolution and the valence band sufficiently positive for oxygen evolution, so that it remains stable under irradiation. This single-junction semiconductor electrode has not yet been discovered. Indeed, it is only with materials with band gaps even larger than that of $\mathrm{TiO}_{2}$, like $\mathrm{SrTiO}_{3}$, that water splitting can be carried out without an additional electrical bias. The solar efficiency of such cells is very small.

D. Semiconductor Particle Systems. A considerable simplification of the apparatus is possible if the electrochemical cell can be replaced by simple dispersions of semiconductor particles. In such dispersions, the semiconductor particles can be coated with islands of metals that behave as catalytic sites, with each particle behaving as a microelectrochemical cell. ${ }^{10} \mathrm{TiO}_{2}$ has been a favorite material, although other compounds, such as CdS and $\mathrm{ZnO}$, have also been studied. While a number of interesting photoreactions have been carried out, including the use of particles to destroy organics and to plate metals from waste water ${ }^{11}$ and for synthetic purposes, ${ }^{12}$ reports on the use of particulate systems for water splitting remain controversial. At best the solar efficiencies of processes reported to date have been very small $(<1 \%)$. An extension of this approach is the use of colloidalsized particles down to nanoparticles (or Q- or quantum-particles) with band gaps larger than that of the bulk material and a function of particle size. Such small particles also have very high surface areas that, in principle, allow faster capture of the photogenerated charges by solution species and with less bulk recombination. To prevent agglomeration of these particles, they are usually capped with polymers or immobilized on an inert support.

E. Sensitized Semiconductor Systems. To overcome the problems of a large band gap and inefficient utilization of the solar spectrum, e.g., with $\mathrm{TiO}_{2}$, dye sensitizers can be adsorbed on the surface of the electrode or particle. ${ }^{13}$ The photon absorbed in the dye creates an electron which passes into the semiconductor, eventually causing a reduction reaction, and the hole is filled by an electron from an adsorbed or solution species in an oxidation reaction (Figure 1D). With a thin film of dye, the quantum efficiency, i.e., the number of electrons injected into the semiconductor per photon absorbed, can be very high. However, with a thin dye layer, even in dyes with high extinction coefficients, only a small fraction of the incident photons are absorbed, so the overall solar efficiency tends to be small (usually $<1 \%$ and more often $<0.1 \%$ ). The total absorbance by the dye layer can be increased by increasing its thickness, but in that case, since most of the photons are absorbed away from the interface between semiconductor and solution and must diffuse and migrate to that site before reaction, the quantum efficiency decreases sharply. A recent advance has been the use of highly porous $\mathrm{TiO}_{2}$ electrodes with very large surface areas ("fractal electrodes") as substrates for the dye sensitizer. ${ }^{14}$ These apparently absorb a

(10) Bard, A. J. J. Photochem. 1979, 10, 59

(11) Photocatalytic Purification and Treatment of Water and Air; Ollis, D. F., Al-Ekabi, H., Eds.; Elsevier: Amsterdam, 1993.

(12) Photocatalysis-Fundamentals and Applications; Serpone, N. Pelizzetti, E., Eds.; Wiley: New York, 1989.

(13) Tributsch, H.; Calvin, M. Photochem. Photobiol. 1971, 14, 95.

(14) Desilvestro, I.: Grätzel, M.; Kavau, L.; Moser, I.; Augustinski, J. J. Am. Chem. Soc. 1985, 107, 2988. 
large fraction of the incident light while still maintaining a high quantum efficiency. A photoelectrochemical cell based on a ruthenium complex sensitizer adsorbed on $\mathrm{TiO}_{2}$ showed an efficiency above $7 \%$ in direct sunlight for conversion of light to electricity. In this example, iodine was generated at the dye-coated electrode and was reduced at the counter electrode. ${ }^{15}$ For water splitting, the oxidation reaction at the dye/ liquid interface would have to generate oxygen, a considerably more difficult process. Indeed, a fundamental problem with dye-sensitized systems may be the photochemical instability of the sensitizer, especially when holes sufficiently energetic to liberate oxygen are produced during irradiation.

F. Homogeneous and Microheterogeneous Systems. An alternative to these electrochemical methods is to employ multicomponent solutions or dispersions as complex arrays for multistep water splitting. Such a system would typically combine an efficient sensitizer, one or more relays or charge accumulation sites, and one or more gas evolution catalysts. Much effort has been devoted to understanding and optimizing the function of each constituent of these arrays, but their combination (even of the best single components) has so far not produced the desired synergism needed to attain the high solar conversion efficiency that is the goal of this quest.

The most thoroughly studied systems employ microheterogeneous arrays, with either the oxidation $\left(\mathrm{H}_{2} \mathrm{O} \rightarrow \mathrm{O}_{2}\right)$ or the reduction $\left(\mathrm{H}_{2} \mathrm{O} \rightarrow \mathrm{H}_{2}\right)$ half-reactions being the targeted goal. In such arrays, the excited state of the sensitizer is quenched either reductively or oxidatively, and most require a sacrificial electron donor or acceptor. A major disadvantage of most systems studied so far is that they do not accomplish true water splitting; rather, they focus on either hydrogen generation in the presence of a sacrificial electron donor or oxygen production in the presence of a sacrificial electron acceptor. Even when optimized, a successful melding of these half-reactions into a simple composite array remains elusive. Furthermore, the consumption of a sacrificial reagent in the optimized half-reactions obviates the economic advantages of simple water splitting and mars its environmental attractiveness as a means for chemical production of fuel by solar energy conversion. Including a sacrificial reagent also often completely reverses the net thermodynamics, converting an inherently uphill (photosynthetic) reaction such as water splitting into a net energetically downhill (photocatalytic) transformation by coupling the endothermic steps with other highly exothermic ones.

In the half-reaction involving the production of hydrogen, the following coupled sequence is typically followed. The key photochemically-driven step is the oxidation of the excited sensitizer $S$, which is accomplished by transferring an electron to a molecule $R$ that acts as a relay to a proton source, usually in the presence of a catalyst Cat. The singly oxidized sensitizer is then reconverted to its original neutral state by interaction with a sacrificial electron donor $\mathrm{D}$, which is consumed in a sequence of one or more chemical steps initiated by irreversible electron donation. The radical anion produced upon oxidation of the sensitizer acts as a relay reagent, transferring its

(15) O'Regan, B.; Grätzel, M. Nalure 1991, 353, 737.

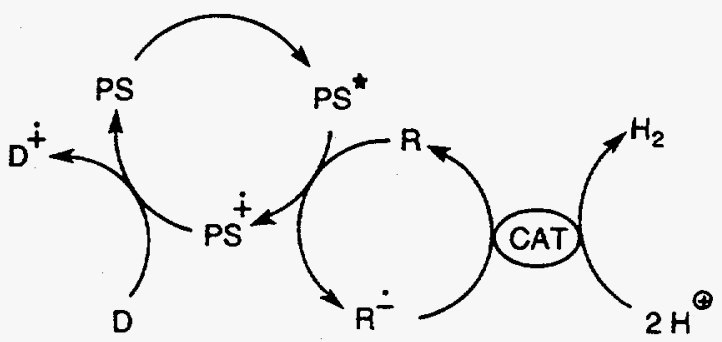

extra electron, usually in the presence of a catalyst, to water, thus producing hydrogen gas. The catalyst thus functions both to accumulate electrons to provide the necessary electrochemical potential and the number of electrons for the reduction of water and to serve as a gas evolution site.

For efficient hydrogen evolution, several features are necessary: (1) the oxidative trapping must occur faster than radiative or nonradiative relaxation of the sensitizer excited state; (2) each of the intermediate charge relays must be stable in both the oxidized and reduced states so that the sensitizing dye can be multiply recycled; (3) a robust catalyst for efficient evolution of hydrogen must be effective in trapping the reduced relay; (4) the sacrificial donor must be inexpensive and readily available; and (5) each of the components of the array must be chemically and optically compatible. In operation, these requirements are often structurally contradictory, and even when a high quantum efficiency (production of fuel per absorbed photon) is observed, low solar efficiency (production of fuel over the entire range of incident photons) is commonly encountered.

Lehn and co-workers have provided an early example of one such ensemble, using a metal complex $\mathrm{Ru}(\mathrm{bpy})_{3} \mathrm{Cl}_{2}$, as sensitizer, triethanolamine as the sacrificial donor, and colloidal platinum generated in situ from $\mathrm{K}_{2} \mathrm{PtCl}_{6}$ as the gas evolution catalyst. ${ }^{16}$ Numerous other variants of these studies were undertaken in the subsequent decade, ${ }^{17}$ with sensitizers including metal complexes, metalated porphyrins and phthalocyanines, organic dyes, (e.g., xanthines or cyanines), or organic polymers [e.g., poly(vinylpyridines)]. In such studies, a range of relays (e.g., viologens, phenanthroline complexes, multivalent cations like $\mathrm{V}^{3+}$ or $\mathrm{Cr}^{3+}$, or redox enzymes like cytochrome $c_{3}$ ) and catalysts (e.g., metal alloys, enzymes, supported metal oxides, colloidal metals, etc.) were employed.

In a typical optimized system [with $\mathrm{Ru}(\mathrm{bpy})_{3} \mathrm{Cl}_{2}$ as sensitizer and methyl viologen as relay for hydrogen evolution on colloidal platinum or gold in the presence of sacrificial ethylenediamine tetraacetic acid (EDTA)], hydrogen evolves efficiently, with catalytic turnover (about 100) limited by competing hydrogenation of the methyl viologen relay. 18 Turnover efficiency could be substantially improved by substituting a family of newly synthesized viologens that are resistant to catalytic hydrogenation ${ }^{19}$ and by replacing the hydrogen evolution catalyst with colloidal platinum. Most studies with these artificial arrays, however, have

(16) Lehn, J.-M.; Sauvage, J.-P. Nouv. J. Chim. 1977, 1, 449.

(17) Grätzel, M. Energy Resources through Photochemistry and Catalysis; Academic Press: New York. 1983.

(18) Moradpour, A.; Amouyal, E.; Keller, P.; Kagan, H. Nouv. J. Chim. $1978,2,547$.

(19) See, for example: Crutchlcy, R. J.; Lever, A. B. P. J. Am. Chem. Soc. 1980, 102, 7128 . 
focused on forward- and back-electron-transfer rates and on structural improvement of photophysical properties: for example, with a complex five-component antenna system, Sasse and co-workers have reported a quantum efficiency of $93 \%$ for hydrogen evolution from an array containing 9-anthracenecarboxylate in acetate buffered to $\mathrm{pH} 5$ in a solution containing EDTA and methyl viologen. ${ }^{20}$

Similarly, oxygen evolution could be induced by irradiation with redox catalysts that act as pools of oxidative equivalents. ${ }^{15,21,22}$ In a recent variant, Calzaferri has employed $\mathrm{Ag}^{+}$-loaded zeolites toward this objective, with self-sensitization by $\mathrm{O}_{2}$ being demonstrated to improve $\mathrm{O}_{2}$ evolution efficiency. ${ }^{23}$ In general, much lower efficiencies are observed for the evolution of oxygen than of hydrogen, mainly because of the difficulty in accumulating the necessary four oxidative equivalents required to convert water to oxygen.

Self-assembling arrays have also been constructed in media in which one or more of the components is confined within a fixed matrix, either a sol-gel or a zeolite. In functionalized zeolites, for example, Mallouk and co-workers have shown that a substantially extended charge separation lifetime of $37 \mu$ s can lead to a quantum efficiency for charge separation of about $17 \%$ from flash photolysis measurements, ${ }^{24}$ although a quantum efficiency for hydrogen evolution of only $0.05 \%$ has been reported by Dutta and co-workers for a similarly constructed array. ${ }^{25}$ Given that very long charge carrier lifetimes (from excitation of pyrene to a viologen confined to a silicate matrix in the presence of a mobile electron relay ${ }^{26}$ ) have been reported, one might expect high efficiencies for hydrogen production in analogous sol-gels if mass transport limitations can be overcome.

Another option to a self-assembling, multicomponent, microheterogeneous array is using a covalent supramolecular assembly to accomplish long-term electron-hole pair separation. Such arrays containing three, four, or five absorbers, relays, or traps have been described by a number of groups as capable of relatively long distance (tens of angstroms) charge separation with high quantum efficiency and long lifetimes (83\% for an electron-transfer pentad with a charge separation lifetime of $55 \mu \mathrm{s}$ in chloroform ${ }^{27}$ ),

(20) Johansen, O.; Mau, A. W. H.; Sass, W. H. F. Chem. Phys. Lett. $1983,94,107,113$.

(21) Lehn, J.-M.; Sauvage, J.-P.; Ziessel, R. Nouv. J. Chim. 1979, 3, 423.

(22) Kalyanasundaram, K; Grätzel, M. Angew. Chem., Int. Ed. Engl. $1979,18,701$.

(23) Sulzberger, B.; Calzaferri, G. J. Photochem. 1982, 19, 321

(24) Krueger, J. S.; Mayer, J. E.; Mallouk, T. E. J. Am. Chem. Soc. $1988,110,8232$

(25) Borja, M.; Dutta, P. K. Nature 1993, 362, 43. 240 .

(26) Slama-Schwork, A.; Ottolenghi, M.; Avnir, D. Nature 1992, 355,

(27) Gust, D.; Moore, T. A.; Moore, A. L.; Lee, S. J.; Bittersmann, E.; Luttrull, D. K.; Rehms, A. A.; DeGraziano, J. M.; Ma, X. C.; Gao, F.; Belford, R. E.; Trier, T. T. Science 1990. 248, 199.

(28) van Damme, H. V. D.; Nijs, H.: Fripiat, J. J. J. Mol. Catal. 1984 27,123 .

(29) Katakis, D. F.; Nitsopoulou, C.; Konstantatos, J.; Vrachnou, E.; Falaras, P. J. Photochem. Photobiol. A (Chem.) 1992, 68, 375.

(30) Smotkin, E.; Cervera-March. S.: Bard, A. J.; Campion, A.; Fox M. A.; Mallouk, T. E.- Webber, S. E.; White, J. M. J. Phys. Chem. 1987 91,6 .

(31) Fan, F.-R. F.; Keil, R. G.; Bard. A. J. J. Am. Chem. Soc. 1983 105,220 .

(32) Nakato, Y.; Ueda, K.; Yano, H.: Tsubomura, H. J. Phys. Chem $1988,92,2316$

(33) Weller, H. Ber. Bunsen-Ges. Phys. Chem. 1991, 95, 1361. with the rate of forward electron transfer favored by a factor substantially greater than $10^{3}$ over the energy dissipative back electron transfer.

Despite the inherent difficulties encountered in attempts to optimize the oxidative and reductive halfreactions in solution phase systems, it is clear that impressive progress has been made. Nonetheless, combinations of such half-reactions to a more complex array capable of water splitting (with concomitant hydrogen and oxygen evolution) have proven to be difficult. To our knowledge, no truly homogeneous nonsacrificial system for water splitting has yet been reported. Even so, compartmentalized tandem oxidation-reduction does take place on several nonelectroactive spatially confined solids, although the catalytic turnover numbers remain small (turnover number of about 5 for a Ru(bpy) $)_{3}{ }^{2+} / \mathrm{clay} / \mathrm{Eu}^{3+}$ array $^{28}$ ), the reactions oscillatory, and the net quantum efficiencies low [4\% upon excitation of tris[1-(4-methoxyphenyl)-2phenylit 1,2-ethylenedithiolenic] tungsten in the visible $\left.^{29}(400-500 \mathrm{~nm})\right]$.

\section{Prospects for the Future}

These scientific difficulties continue to pose tantalizing challenges to scientists bent on devising commercially viable means for solar energy conversion, especially as it relates to chemical fuel production and its contribution to a hydrogen-based economy. Although we claim no special insight into the ultimate solutions to these problems, we can speculate on those research directions that may seem most promising. Given the difficulties associated with homogeneous routes employed so far, it is a fair bet that heterogeneous arrays will be needed for high-efficiency solar energy conversion. The problem of accumulating multiple redox equivalents for the oxidation and reduction half-reactions also suggests that these systems will require multifunctional components. One possibility is the use of multijunction devices, such as the bipolar $\mathrm{CdSe} / \mathrm{CoS}$ semiconductor photoelectrode panel array on which unassisted water photodecomposition can be stoichiometrically attained with an equivalent solar energy efficiency of about $1 \% .30$ It is also likely that new semiconductor materials and multielectron catalysts will be key components of such heterogeneous arrays, perhaps with small metal clusters or films to protect the semiconductor surface, for example, as noble metal silicides ${ }^{31}$ or microscopically discontinuous metal overlayers. ${ }^{32}$ Dramatically new families of photosensitizers might also overcome some of the practical barriers still encountered in attempts to utilize the whole solar spectrum: the use of nanoparticles of one semiconductor on a highly porous film of $\mathrm{TiO}_{2}{ }^{33}$ seems a very interesting possibility. In any case, it seems clear that a creative breakthrough, probably focused within the boundaries defined by intriguing basic research conducted over the last decade, is needed to reach this "Grail".

M.A.F. gratefully acknowledges useful discussions on these and related topics with Dr. Edmond Amouyal (Orsay, France).

AR9400812 


\section{ARTIFICIAL PHOTOSYNTHESIS PUBLICATIONS \\ Structural Biology Division \\ (formerly Chemical Biodynamics Division) \\ Ernest Orlando Lawrence Berkeley National Laboratory \\ University of California, Berkeley, California}

1. Electrochemistry of Excited Molecules: Photoelectrochemical Reactions of Chlorophylls. Helmut Tributsch and Melvin Calvin. Photochem. Photobiol. 14, 95 (1971).

2. Solar Radiation and Life. Melvin Calvin. In "Progress in Photobiology", G. O. Schenck (ed). Deut. Gesell. Lichtforsch. Hamburg, Germany (1974).

3. Research on the Mechanism of Photosynthesis. Melvin Calvin. In "The Current State of Knowledge of the Photochemical Formation of Fuel", National Science Foundation, Washington, DC, Sept. 1974, pp 139-148.

4. Solar Energy by Photosynthesis. Melvin Calvin. Science, 184, 375 (1974).

5. Photosynthesis as a Resource for Energy and Materials. Melvin Calvin. Photochem. Photobiol. 23, 425 (1976).

6. Electron Transfer at Sensitized $\mathrm{TiO}_{2}$ Electrodes. Mark T. Spitler and Melvin Calvin. J. Chem. Phys. 66, 4297 (1977).

7. Adsorption and Oxidation of Rhodamine B at ZnO Electrodes. Mark T. Spitler and Melvin Calvin. J. Chem. Phys. 67, 5193 (2977).

8. Simulating Photosynthetic Quantum Conversion. Melvin Calvin. Acct. Chem. Res. 11, 369 (1978).

9. Photosensitized Electron Transport Across Phospholipid Vesicle Walls. W. E. Ford, J. W. Otvos and Melvin Calvin. Nature, 274, 507 (1978).

10. Photoeffects in $\mathrm{Fe}_{2} \mathrm{O}_{3}$ Sintered Semiconductors. K. G. McGregor, Melvin Calvin and J. W. Otvos. J. Appl. Phys. 50, 369 (1979).

11. Synthetic Chloroplasts. Melvin Calvin. Energy Res. 3, 73 (1979).

12. Quenching of Rhodamine 101 Emission in Methanol and in Colloidal Suspensions of Latex Particles. A. J. Frank, J. W. Otvos and Melvin Calvin. J. Phys. Chem. 86, 7816 (1979).

13. Plant Photochemistry--As Such and as Model. Melvin Calvin. R. A. Welch Found. Conf. Proc. 22, 7 (1979).

14. Photoinduced Electron Transfer Across a Water-Oil Boundary: A Model for Redox Reaction Separation. I. Willner, W. E. Ford, J. W. Otvos and Melvin Calvin. Nature 280, 828 (1979).

15. Photosensitized Electron Transport Across Lipid Vesicle Walls: Quantum Yield Dependence of Sensitizer Concentration. W. E. Ford, J. W. Otvos and Melvin Calvin. Proc. Natl. Acad. Sci USA 76, 3590 (1979).

16. Simulation of Photosynthesis: A Resource for Energy. I. Willner, W. E. Ford, J. W. Otvos and Melvin Calvin. In "Bioelectrochemistry", H. Kuyzer and F. Gutmann (eds). Plenum Press, New York (1980), pp 55-81.

17. Visible Spectra of Dicarbonyl Substituted Tris-Bipyridyl Ruthenium(II) Complexes. W. E. Ford and Melvin Calvin. Chem. Phys. Let. 76, 105 (1980).

18. Preparation of Oxoporphinatomanganese(IV) Complex. I. Willner, J.W. Otvos and Melvin Calvin. J.C.S. Chem. Commun. 964 (1980).

19. Synthetic Chloroplasts. Melvin Calvin. Faraday Soc. Disc. 70, 383 (1980).

20. An Improved Synthesis of Surfactant Porphyrins. Yohmei Okuno, W. E. Ford and Melvin Calvin. Synthesis 7, 537 (1980).

21. Photosensitized Electron Transfer Reactions in Colloidal $\mathrm{SiO}_{2}$ Systems: Charge Separation at a Solid-Aqueous Interface. I. Willner, J.W. Otvos and Melvin Calvin. J. Amer.Chem.Soc. 103, 3203 (1981). 
22. Photosensitized Electron Transport Across Lipid Vesicle Walls: Enhancement of Quantum Yield by Ionophores by Transmembrane Potentials. Colja Laane, W. E. Ford, J. W. Otvos and Melvin Calvin. Proc. Natl. Acad. Sci. USA 78, 2017 (1981).

23. Solar Induced Water Splitting with p/n Heterotype Photochemical Diodes: $\mathrm{n}-\mathrm{Fe}_{2} \mathrm{O}_{3} / \mathrm{p}-\mathrm{GaP}$. Howard Mettee, J. W. Otvos and Melvin Calvin. Solar Energy Mater. 4, 443 (1981).

24. Photoactivation of $\mathrm{O}$ and Evolution of $\mathrm{O}_{2}$. Melvin Calvin. In "Oxygen and Life", Royal Soc. Chem. Spec. Pub. 39, 45 (1981).

25. Photosensitized Electron Transfer Processes in $\mathrm{SiO}_{2}$ Colloids and NaLS Micellar Systems: Correlation of Quantum Yields with Interfacial Surface Potentials. C. Laane, I. Willner, J. W. Otvos and Melvin Calvin. Proc. Natl. Acad. Sci. USA 78, 5928 (1981).

26. Photosensitized Electron Transfer Reactions in Organized Interfacial Systems. M. Calvin, I. Willner, C. Laane and J.W. Otvos. J. Photochem. 17, 195 (1981).

27. The Function of $\mathrm{SiO}_{2}$ Colloids in Photoinduced Redox Reactions: Interfacial Effects on Quenching, Charge Separation and Quantum Yield. I. Willner, C. Laane, Jer-Ming Yang, J. W. Otvos and Melvin Calvin. J. Phys. Chem. 85, 3277 (1981).

29. Simulating Photosynthetic Quantum Conversion. Melvin Calvin. In "Photochemical Conversion and Storage of Solar Energy", J. S. Connolly (ed), Academic Press, New York (1981), pp 1-26.

30. Bioconversion of Solar Energy. Melvin Calvin. In "Trends in Photobiology", C. Helene, M.Charlier, Th. Montenay-Garestier and G. Laustriat (eds). Plenum Press, New York (1982), pp 645-659.

31. Control of Photosensitized Electron Transfer Reactions in Organized Interfacial Systems: Vesicles, Water-in-Oil Microemulsions and Colloidal $\mathrm{SiO}_{2}$ Particles. I. Willner, C. Laane, J. W. Otvos and Melvin Calvin. In "Inorganic Reactions in Organized Media", ACS Symposium Series 177, 71 (1982).

32. Environmental Influences on the Photooxidation of Manganese by a Zinc Porphyrin Sensitizer. Roland Wohlgemuth, John W. Otvos and Melvin Calvin. Proc. Natl. Acad. Sci. USA 79, 6144 (1981).

33. Photovoltaic Properties of Au-Mercocyanine-TiO 2 Sandwich Cells. I. Dark Electrical Properties and Transient Effects. T. Skotheim, J.-M Y ang and M. P. Klein. J. Chem. Phys. 77, 6144 (1982).

34. Photovoltaic Properties of Au-Mercocyanine-TiO $\mathrm{O}_{2}$ Sandwich Cells. II. Properties of Illuminated Cells and Effects of Doping with Electron Acceptors. T. Skotheim, J.-M. Yang, J. W. Otvos and M. P. Klein. J. Chem. Phys. 77, 6151 (1982).

35. Artificial Photosynthesis: Quantum Capture and Energy Storage. Melvin Calvin. Photochem. Photobiol. 37, 349 (1983).

36. Quantum Capture and Redox Storage. Melvin Calvin. Can J. Chem. 61 (5), 83 (1983).

37. Preparation of Zwitterionic Electron Acceptors and Donors. Itamar Willner and William E. Ford. J. Heterocyclic Chem. 20, 1113 (1983).

38. Temperature Dependence of Photosensitized Electron Transport Across Lipid Vesicle Walls. H. D. Mettee, W. E. Ford, T. Sakai and Melvin Calvin. Photochem. Photboiol. 39, 679 (1984).

39. Artificial Photosynthesis: Quantum Capture and Redox Storage. Melvin Calvin and Y. Okuno. Kagaku (Tokyo) 54, 139 (1984).

40. Surfactant Manganese Complexes as Models for the Oxidation of Water. Roland Wohlgemuth, John W. Otvos and Melvin Calvin. Adv. Photosyn. Res. Proc. 
Int. Congr. Photosyn. 6th, 1, 745 (1984).

41. Polyelectrolytes as Interfaces for Retarding Backreaction in Photoinduced Electron Transfer. J. W. Otvos, T. E. Casti and Melvin Calvin. Sci. Papers Inst. Phys. Chem. Res. (Japan), 78, 129 (1984).

42. The Effects of Dimensionality on Solar Spectrum Curves. T. E. Casti and J. W. Otvos. J. Chem. Educ. 63, 35 (1986).

43. Synthesis and Characterization of a Mn(III) Porphyrin Cation Radical and Its Conversion to Mn(IV) by Ligand Metathesis. L. O. Spreer, A. C. Maliyackel, S. Holbrook, J. W. Otvos. and Melvin Calvin. J. Amer. Chem. Soc. 108, 1949 (1986).

44. Preparation and Properties of Porphyin-Modified Hollow Fiber Membranes for Use as Heterogeneous Photosensitizers for Singlet Oxygen and for Artificial Photosynthesis. Carl C. Wamser, Melvin Calvin and G. A. Graf. J. Membrane Sci. 28, 31 (1986).

45. Photoinduced Oxidation of a Water-Soluble Manganese(III) Porphyrin. Anthony C. Maliyackel, John W. Otvos, Larry O. Spreer and Melvin Calvin. Proc. Natl. Acad. Sci. USA 83, 3572 (1986).

46. Photoinduced Behavior of Zinc and Manganese Porphyrins in Dihexadecyl Phosphate and L- $\gamma$-Phosphatidyl-DL Glycerol Vesicular Systems. R. Rafaeloff, A. C. Maliyackel, J. L. Grant, J. W. Otvos and Melvin Calvin. Nouv. J. Chim. 10, 613 (1986).

47. Biological and Biomimetic Systems. J. W. Otvos. Nouv. J. Chim. 11, 195 (1987).

48. Artificial Photosynthesis. Melvin Calvin. J. Membrane Sci. 33, 137 (1987).

49. The Photochemical Reduction of Carbon Dioxide to Carbon Monoxide in Water Using a Ni(II)Tetraazamacrocycle Complex as Catalyst. Janice L. Grant, Larry O. Spreer, John W. Otvos and Melvin Calvin. J. Chem.Soc.Dalton Trans. 2105 (1987).

50. Temperature-Dependent Valence Isomerization in a Manganese Tetraphenyl Porphyrin. Anthony C. Maliyackel, John W. Otvos, Melvin Calvin and Larry O. Spreer. Inorg. Chem. 26, 4133 (1987).

51. Chemistry of a High Oxidation Level Manganese Porphyrin in Aqueous Solution. L. O. Spreer, A. Leone, A. C. Maliyackel, J. W. Otvos and Melvin Calvin. Inorg. Chem. 27, 2401 (1988).

52. Synthesis and Properties of Two Bimetallic Mixed-Valence Di- $\mu$-oxo Manganese Complexes with Different Tetraaza Macrocyclic Ligands. Karen J. Brewer, Angele Liegeois, John W. Otvos, Melvin Calvin and Larry O. Spreer. J. Chem. Soc. Chem. Commun. 1219 (1988).

53. Synthesis, Structure, and Characterization of a Mixed-Valence Manganese(III)-

Manganese(IV) Bis( $\mu$-oxo) Complex with a Macrocyclic Tetraaza Ligand. Karen J. Brewer, Melvin Calvin, Richard S. Lumpkin, John W. Otvos and Larry O. Spreer. Inorg. Chem. 28, 4446 (1989).

54. The Crystal Structure of $\left[\mathrm{Ni}\left(12-\mathrm{aneN}_{4}\left(\mathrm{OH}_{2}\right)_{2}\right]\left(\mathrm{ClO}_{4}\right) \mathrm{H}_{2} \mathrm{O}\right.$ : Novel Conformation for a Coordinated Macrocycle. Brian Scott, Karen J. Brewer, Carl A. Craig, Larry O. Spreer, John W. Otvos, Melvin Calvin and Scott E. Taylor. J. Coord. Chem. 21, 307 (1990).

55. Photochemical Reduction of Carbon Dioxide Using Nickel Tetraazamacrocycles. Carl A. Craig, Larry O. Spreer, John W. Otvos and Melvin Calvin. J. Phy. Chem. 94, 7957 (1990).

56. Structure and Properties of a Bimetallic Complex with a Conjugated Bridge Between Iron Atoms in Two Macrocycles. H. Scott Mountford, Larry O. Spreer, John W. Otvos, Karen J. Brewer, Mark Richtrer and Brian Scott. Inorg. Chem. 31, 717 (1992). 
57. Evidence for a New Valence-Averaged Di-Ruthenium Complex. Larry O. Spreer, C. B. Allan, D. B. MacQueen, J. W. Otvos and M. Calvin. J. Amer. Chem. Soc. 116,2187 (1994).

58. Characterization of a Delocalized Mixed-Valence Bis-macrocyclic Di-iron Compound. Larry O. Spreer, Aiping Li, D. Brent MacQueen, Christian B. Allan, John W. Otvos, Melvin Calvin, Richard B. Frankel and Georgia C. Papaefthymiou. Inorg. Chem. 33, 1753 (1994).

59. Spectroscopic and Electrochemical Characterization of a Bis-Macrocyclic Di-iron Compound. H. Scott Mountford, D. Brent MacQueen, Aiping Li, John W. Otvos, Melvin Calvin, Richard B. Frankel and Larry O. Spreer. Inorg. Chem. 33, 1748 (1994).

60. Axial Ligand Effects on Redox Properties of a Strongly Coupled bis-Macrocyclic Diiron Compound. J. Zhou, A. Li, C. Lange, C. B. Allan, L. O. Spreer, J. W. Otvos and M. Calvin. Inorg. Chim. Acta,

61. Reaction of Dioxygen with a Cross-Conjugated Carbon-Carbon Double Bond in a bis-Macrocyclic Diiron Compound. D. Brent MacQueen, Christopher Lange, Melvin Calvin, John W. Otvos, Larry O. Spreer, Christian B. Allan, Anna Ganse and Richard B. Frankel. Inorg. Chem. 


\section{ARTIFICIAL PHOTOSYNTHESIS PUBLICATIONS \\ Lawrence Berkeley National Laboratory Reports}

1. Vectorial Photoinduced Electron Transfer Processes in Aqueous $\mathrm{SiO}_{2}$ Colloids: Efficient Separation of Photoproducts. I. Willner, Jer-Ming Yang, J. W. Otvos and Melvin Calvin. LBL 12358, March 1981.

2. Hollow Fiber Membranes for Photosensitized Electron Transport. Carl C. Wamser, John W. Otvos and Melvin Calvin. LBL 12359, March 1981.

3. Kinetics of Photosensitized Electron Transport Across a Membrane Boundary. Carl C. Wamser, John W. Otvos and Melvin Calvin. LBL 12360, March 1981.

4. Magnetic Field Effects on Photosensitized Reactions. Carl C. Wamser, John W. Otvos and Melvin Calvin. LBL 12361, March 1981.

5. Coupled Electron Transfer Reactions in $\mathrm{SiO}_{2}$ Colloids: Enhancement of Quantum Yields. I. Willner, Jer-Ming Yang, J.W. Otvos and Melvin Calvin. LBL 13215, August 1981.

6. Crystal and Molecular Structure of Chloro-bis-N-butyl-3-fluorosalicylaldimato Manganese(III).Roland Wohlgemuth, Fred Hollander, John W. Otvos and Melvin Calvin. LBL 16814, May 1983.

7. Photoinduced Electron Transfer Reacations of Membrane-Anchored Zinc and Manganese Porphyrins. R. Rafaeloff, A. C. Maliyackel, J. L. Grant, J. W. Otvos and Melvin Calvin. LBL 21278, March 1986.

8. Fuel Cell Oxygen Sensor for Trace Oxygen Analysis. Anthony Leone, John W. Otvos and Melvin Calvin. LBL 23664, June 1987.

9. Photophysical and Photochemical Aspects of the Binding of Zinc Porphyrin to Sodium Poly(Styrene Sulfonate). Kisholoy Goswami, Thomas E. Casti, John W. Otvos and Melvin Calvin., LBL 23885, August 1987. 


\section{ARTIFICIAL PHOTOSYNTHESIS THESES}

1. Electron Transfer at Sensitized Semiconductor Electrodes. Mark Thomas Spitler March 1977.

2. Photovoltaic Properties of Metal-Mercocyanine-TiO 2 Sandwich Cells. Terje A. Skotheim. November 1979.

3. Photoinduced Electron Transfer Reactions in Heterogeneous Media. Jer-Ming Yang. November 1981.

4. Energy Interactions and Phospholipid Vesicles. David Edmund Baker (M.S. thesis). June 1982

5. Photosensitized Electron Transport Across Lipid Vesicle Walls. William Ellsworth Ford. November 1982

6. Photoinduced Electron Transfer in Rigid Solution: Time-Resolved Quenching of Triplet Zinc Tetraphenylporphine. Michael Arthur Kablow (M.S. thesis). January 1984.

7. Environmental Effects on Photoinduced Electron Transfer Reaction s. Thomas Edward Casti. December 1985. 


\section{ARTIFICIAL PHOTOSYNTHESIS GROUP Structural Biology Division \\ (Formerly Chemical Biodynamics Division) \\ Ernest Orlando Lawrence Berkeley National Laboratory \\ University of California \\ Berkeley, California 94720}

$1970-1995$

Principal Investigators (during entire period)

Professor Melvin Calvin

Dr. John W. Otvos

Year(s) Name

1970-71 Helmut Tributsch

1975-76 Saul Alkaitis

Jelmer Miedema

1976-77 Yohmei Okuno

1977-78 Steven Cooper

Arthur Frank

Kevin McGregor

James Grant

Itamar Willner

1978-79 Colja Laane

Howard Mettee

Itamar Willner

1979-1980 Colja Laane

Itamar Willner

Roland Wohlgemuth

1980-81 Colja Laane

Carl E. Wamser

Itamar Willner

Roland Wohlgemuth

1981-1982 Roland Wohlgemuth

1982-1983 Stephen L. Rodgers

Ching-Bore Wang

Roland Wohlgemuth

1983-84
Janice Grant

Anthony Maliyackel

Larry Spreer

Ching-Bore Wang
Current Address

(if known)

Hahn-Meitner Institute, Berlin, Germany

National Chemical Laboratory of Industry, lbaraki, Japan

Mallinckrodt Chemical/Medical, St. Louis, MO

National Renewable Energy Laboratory, Golden, CO

Hebrew University, Jerusalem, Israel

Unilever Research Laboratorium, The Netherlands

Youngstown State University, Youngstown, OH

Fluka AG, Buchs, Switzerland

Portland State University, Portland, OR

Micro Lithography, San Leandro, CA

Bangkok, Thailand

Sun Chemical Co., Cincinnati, $\mathrm{OH}$

University of the Pacific, Stockton, CA 
1984-85 Janice Grant Anthony Maliyackel

Rafael Rafaeloff

Larry Spreer

1985-86 Janice Grant

Anthony Leone Lockheed Missiles \& Space Co., Mountain View,

Anthony Maliyackel

Rafael Rafaeloff

Larry Spreer

1986-87 Kisholoy Goswami Physical Optics Corp.,Torrance, CA

Anthony Maliyackel

Rafael Rafaeloff

Larry Spreer

1987-1988 Karen Brewer Virginia Polytechnic Institute, Blacksburg, VA

Carl Craig

Rafael Rafaeloff (3 months)

Okiyasu Shimizu Nagoya City University, Nagoya, Japan

Larry Spreer

1988-89 Carl Craig

Richard Lumpkin University of Alabama, Huntsville, AL

Okiyasu Shimizu

Larry Spreer

1989-90 Richard Lumpkin

Larry Spreer

1990-91 Brent MacQueen National Renewable Energy Laboratory, Golden, CO Rafael Rafaeloff (2 months)

Larry Spreer

1991-92 Brent MacQueen

Larry Spreer

1992-93 Brent MacQueen

Larry Spreer

1993-94 Christopher Lange Life Sciences Division, Lawrence Berkeley

Larry Spreer

National Laboratory,

1994-95 Christopher Lange (through January)

Larry Spreer 
Graduate Students

\begin{tabular}{|c|c|c|}
\hline 1977 & Mark T. Spitler & Polaroid Corp., Cambridge, MA \\
\hline 1979 & Terje A. Skotheim & MOLTECH, Inc., Tucson,AZ \\
\hline 1981 & Jer-Ming Yang & $\begin{array}{l}\text { Industrial Technology Research Unit, Advanced } \\
\text { TechnologyDevelopment Dept., Chuting, Hsinchu, } \\
\text { Taiwan }\end{array}$ \\
\hline 1982 & David E. Baker & M.S. degree \\
\hline & William E. Ford & $\begin{array}{l}\text { Bowling Green State University, Bowling Green, } \\
\text { OH }\end{array}$ \\
\hline 1984 & $\begin{array}{l}\text { Michael A. Kahlow } \\
\text { Thomas E. Casti }\end{array}$ & $\begin{array}{l}\text { M.S. degree } \\
\text { Hercules Inc., Wilmington, DE }\end{array}$ \\
\hline
\end{tabular}




\section{INDEX}

\section{Journal Articles/Book Chapters/Reviews}

\section{Name}

Allan, Christian B.

Brewer, Karen J.

Calvin, Melvin

Craig, Carl A.

Ford, William E.

Frank, Arthur F.

Frankel, Richard B.

Graf, G. A.

Grant, Janice L.

Holbrook, Stephen

Klein, Melvin P.

Lange, Christopher

Leone, Anthony

Li, Aiping

Liegeois, Angele

Lumpkin, Richard S.

MacQueen, D. Brent

Maliyackel, Anthony C.

McGregor, Kevin G.

Mettee, Howard

Mountford, H. Scott

Okuno, Yohmei

Otvos, John W.

Papaefthymiou, Georgia C.

Rafaeloff, Rafael

Richter, Mark

Sakai, T.

Scott, Brian

Skotheim, Terje

Spitler, Mark T.

Spreer, Larry O.

Taylor, Scott E.

Tributsch, Helmut

Willner, Itamar

Wohlgemuth, Roland

Yang, Jer-Ming

Zhou, J.
Publication Number

$57,58,60,61$

$52,53,54,56$

$1,2,3,4,5,6,7,8,9,10,11,12,13,14,15,16$, $17,18,19,20,21,22,23,23,25,26,27,28,29$, $30,31,32,35,36,38,39,40,42,43,44,45,46$, $48,49,50,51,52,54,55,56,57,58,59,60,61$ 54,55

$9,14,15,16,17,20,22,37,38$

12

$58,59,60$

44

46,49

43

33,34

60,61

51

$58,59,61$

52

52,53

$57,58,59,60$

$43,45,46,50,51$

10

22,38

56,59

20,39

$9,10,22,14,15,18,21,22,23,25,26,27,31$

$32,34,38,40,41,43,45,46,47,49,50,52,53$

$54,55,56,57,58,59,60,61$

58

46

56

38

54,56

33,34

6,7

$43,45,49,51,52,53,55,56,57,58,59,60,61$

54 ,

1

$14,16,18 \mathrm{k} 21,25,26,27,31,37$

32,40

$27,33,34$

61 


\section{INDEX}

\section{Lawrence Berkeley Laboratory Reports}

Name

Calvin, Melvin

Casti, Thomas E.

Goswami, Kisholoy

Grant, Janice L.

Hollander, Fred

Leone, Anthony

Maliyackel, Anthony C.

Otvos, John W.

Rafaeloff, Rafael

Wamser, Carl E.

Willner, Itamar

Wohlgemuth, Roland

Yang, Jer-Ming
Report Number

$1,2,3,4,5,6,7,8,9$

9

7

5

8

9

$1,3,4,5,6,7,8,9$

7

$2,3,4$

1,5

6

1,5

\section{INDEX}

\section{Theses}

\section{Name}

Baker,David E.

Casti, Thomas E.

Ford, William E.

Kahlow, Michael A.

Skotheim, Terje

Spitler, Mark T.

Yang, Jer-Ming

\section{Thesis Number}

4 (M.S. thesis)

7

5

6 (M.S. thesis)

2

1

3 